\title{
LA TIERRA AGRARIA EN MOZAMBIQUE: EL RÉGIMEN JURÍDICO DE LOS DUAT ${ }^{{ }^{*}}$
}

María José Cazorla González

Prof. Tiular de $\mathrm{D}^{\mathbf{o}}$ civil (UAL-SEJ 235)

E-mail: mcazorla@ual.es

Eduardo A. Chiziane

Prof. $\mathrm{D}^{\circ}$ Administrativo (UEM)

E-mail: eduardochiziane@,hotmail.com

\begin{abstract}
RESUMEN: La tierra agraria y su explotación tiene un régimen jurídico distinto en Mozambique, pues al pertenecer al Estado su naturaleza es publica, y no se le aplica el régimen jurídico de la propiedad privada bajo el limite de la función publica como sucede en España. El presente trabajo tiene como finalidad la descripción de la regulación actual en Mozambique comparándola con España, y analizando ventajas e inconvenientes, tanto en la titularidad individual como local o comunitaria del derecho de uso y disfrute de la tierra, cuyo régimen jurídico se basa en el Derecho privado.
\end{abstract}

Palabras clave: Tierra agraria; derecho de uso y disfrute; propiedad; comunidad local; derecho de uso y disfrute de la tierra.

\begin{abstract}
Agricultural land and its exploitation has a different legal regime in Mozambique, as it belongs to the State and therefore is public in nature, and the legal regime of private property under the limit of the public function does not apply to it as it does in Spain. The purpose of this paper is to describe the current regulations in Mozambique, comparing them with Spain, and analysing the advantages and disadvantages, both in terms of individual and local or community
\end{abstract}

Keywords: Farm; use and enjoyment of property; local community; the right to use and enjoy land.

$1{ }^{*}$ Trabajo desarrollado com investigacion en tres proyectos: Proyecto investigación con referencia AGL201783551-R “Greensoil” financiado en la convocatória PPUENTE2019/005. Proyecto de Investigación de Excelencia de la Consejería de Economía y Conocimiento de la Junta de Andalucía "Retos y oportunidades en la concentración e integración de empresas agroalimentarias” (P12-SEJ-2555). Proyecto de cooperación AECID “Apoyo jurídico al desarrollo rural de Mozambique". A1/035733/11. 


\begin{abstract}
SUMARIO: I. La Constitución de la RepÚblica Popular de Mozambique y la tierRa. II. El derecho de PROPIEDAD DEL ESTADO SOBRE LA TIERRA EN MozambiQUE. 2.1. ANTECEDENTES. 2.2. CONTENIDO DEL DERECHO A LA PROPIEDAD DEL ESTADO SOBRE LA TIERRA. 2.3. NATURALEZA JURÍDICA DE LA PROPIEDAD DEL ESTADO SOBRE LA TIERRA. III. ANÁLISIS COMPARADO CON OTROS PAÍSES DEL RÉGIMEN JURÍDICO DE LA TIERRA AGRARIA. 3.1. FORMAS DE USO Y APROVECHAMIENTO DE LA TIERRA EN TIMOR-LESTE COMO COLONIA PORTUGUESA. 3.2. ForMAS DE USO Y APROVECHAMIENTO

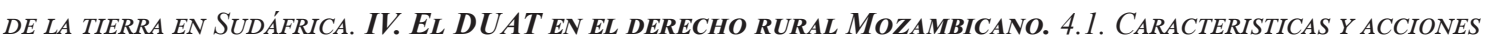
DE PROTECCIÓN DE LOS DUAT. 4.2. LA POSESIÓN DE HECHO Y DE DERECHO. 4.3. PROTECCIÓN DE LA POSICIÓN ACTIVA CONTRA TERCEROS. 4.4. LA EXISTENCIA DE POSICIONES PASIVAS QUE PERTENECEN A LOS NO TITULARES DEL DERECHO. V. FACULTADES DEL TITULAR DEL DUAT. VI. LA NATURALEZA JURÍDICA DEL DUAT Y SU RELACIÓN CON OTROS DERECHOS REALES. 6.1. DERECHO DE POSESIÓN Y DUAT. 6.2. DERECHO DE PROPIEDAD Y DUAT 6.3. DERECHO DE USUFRUCTO Y DUAT. 6.4. DERECHO DE USO Y DISFRUTE Y DUAT. 6.5. EL DUAT Y ENFITEUSIS. 6.6. DERECHO DE SUPERFICIE Y DUAT. VII. NATURALEza JURÍDiCA DEL DUAT. 7.1. LA TESIS DEL DUAT COMO VERDADERO DERECHO REAL. 7.2. LA TESIS DE LA PROXIMIDAD CON EL DERECHO DE PROPIEDAD. 7.3. LA TESIS DEL DERECHO REAL SUI GENERIS. 7.4. LA TESIS DE UN DERECHO REAL DE NATURALEZA HIBRIDA O MIXTA. VIII. EL FUTURO DEL DUAT. 8.1. LA JUSTIFICACIÓN PARA LA CREACIÓN DEL DUAT. 8.2 NECESIDADES PARA MANTENER O REFORMAR EL DUAT. IX. CONCLUSIón. X. Bibliografía
\end{abstract}

\title{
I LA CONSTITUCIÓN DE LA REPÚBLICA POPULAR DE MOZAMBIQUE Y LA TIERRA
}

La primera Constitución de Mozambique, de 1975 se caracteriza por la estratificación de la tierra según el uso y disfrute del régimen a que fueron sometidos, en particular, de la tierra bajo propiedad privada, tierras bajo el régimen de dominio público y el bloque de tierra bajo el régimen de las normas consuetudinarias de diferentes órdenes.

De hecho, la Constitución de 1975 (CRPM 1975), redactada con metas y objetivos nacionalizadores, fue particularmente ejemplar sobre la cuestión de la tierra y otros recursos naturales para que fueran declaradas propiedad del Estado ${ }^{2}$. De tal manera, que consideraba bajo el marco constitucional la extinción de todos los derechos propiedad de la tierra que pudiera existir al margen de la propiedad pública, sin establecerse fecha para la correspondiente compensación o la indemnización, tras la nacionalización de las tierras agrarias.

Este proceso fue muy complejo en la práctica, porque los exterratenientes, dejaban de ser propietarios para obtener un titulo de posesión dirigido a utilizar "sus" tierras, cuya propiedad a partir de la entrada en vigor de la Constitución pasaban a ser de titularidad pública.

Por su parte, la ley de la Tierras de 1979 expresamente, preveía la posibilidad de renovación de estos derechos ${ }^{3}$, es decir, continuar los derechos sobre la tierra bajo el nuevo orden constitucional.

Sin embargo, con la llegada de la la Constitución de la República de Mozambique en 1990, o CRM-1990, se crearon las condiciones y justificación para que una nueva política de tierras descrita y adoptada en el país ${ }^{4}$, fuera de naturaleza pública, donde sorprendentemente se reconoce de manera expresa la propiedad privada, como uno de los pilares sobre los que descansa el orden económico y legal del Estado de Mozambique.

2 Cfr. articulo 8 de la CRPM (1975).

3 Cfr. Artículos 41 de la Ley n. ${ }^{\circ}$ 6/79, de 3 de Julio y su Reglamento 79 y ss. (Dec. N. ${ }^{\circ}$ 16/87 de 13 de Julio).

4 Articulo 41 de la CRM - 1990. 
La Constitución de los 90 viene afirmando lo siguiente:

- En primer lugar, la tierra es propiedad del Estado, entendido como comunidad estatal (estado de la comunidad), y no como aparato administrativo, tal y como se regula bajo los Artículos $46^{\circ}$ y $47^{\circ}$ número 1 .

- En segundo lugar, los derechos de las personas en la tierra se materializan en poderes y prerrogativas conocidos como derecho de uso y disfrute de la tierra (números del art. 2 párrafo 1 y 47) ${ }^{5}$, también denominado aquí por la DUAT (Derecho de uso y aprovechamiento de la tierra), es "cariñosamente" tratado sobre la práctica burocrática el gobierno de Mozambique, particularmente en el nivel de DINAT (Dirección Nacional de Tierras) ${ }^{6}$ y últimamente, también dedicada casi al nivel de nuestro colegio. Sin embargo, la diferencia con los recursos naturales ${ }^{7}$, es que la tierra es regulada constitucionalmente, mientras que los recursos naturales quedan fuera del marco del dominio público, sin que esto implique que la tierra pueda ser considerada como un derecho disponible, porque atendiendo a las limitaciones constitucionales que se impusieron por el estado, tanto a los individuos con respecto a tierra, como las prohibiciones de venta, hipoteca, accesorio o recurrencia a otros esquemas de venta (artículo $46^{\circ}$ número 2 ), el régimen de la tierra en Mozambique, se ubica en el dominio público.

- En tercer lugar y, de acuerdo con anteriormente señalado, el estado de la administración es básicamente administrar la tierra, así como establecer su disciplina particular $\left(47^{\circ}\right.$, números 1 y 3 y $\left.48^{\circ}\right)$, considerada como una ley económica fundamental, entendida desde el derecho de acceso a la riqueza y bienestar social, cuya titularidad y ejercicio es, en principio, independiente de la voluntad y el poder discrecional del Estado (arts. 46, número 3 y art. 48). Donde todos los ciudadanos, independientemente de su sexo, raza, nacionalidad u otra condición social o física, igualan de trato ante la ley (art. $66^{\circ}$ ) si impone en el currículum de Constitución agrario este principio de la igualdad, permitiendo a todos el acceso equitativo a tierra debajo de sus respectivos fines sociales (arts. $39^{\circ}, 42^{\circ}$ y $47^{\circ}$, número 2 ).

- En cuarto lugar, la tierra es para aquellos que trabajan o usan, de manera que no se permite que, sirva como un medio económico o algún privilegio en la mayoría de los ciudadanos, o la posesión de unos pocos a expensas de la mayo-

5 En consonancia con la tradición de la CRPM y la ley del Tierra de 1979.

6 Institución ubicada en el Ministerio de la Tierra, Medio Ambiente y Desarrollo Rural (MITADER) y principal instrumento del gobierno en la administración y gestión de la tierra, siendo especialmente responsable de tramitar las solicitudes de autorización de ocupación de la tierra. Antigua Dirección Nacional de geografía y Catastro.

7 Cfr. El articulo 35 de la CRM-1990. 
ría, o a la exclusión de otros Aquí, teniendo en cuenta el principio de equidad y justicia social. (art. $47^{\circ}$, número 3 y art. $6^{\circ}$, letra c).

- Por último, la propiedad de la tierra, como derecho real, es posible en el ámbito del derecho privado siempre que se refiera al derecho de uso y disfrute de la tierra (art. 47, número 2).

Las diferencias con la Constitución española, son evidentes, pues mientras en ella, se regula la propiedad privada ligada a la función social, en Mozambique se regula bajo propiedad pública. Si bien tienen en común, la función social, procurando legislar para que la finca o explotación, sea acorde a la función económica y en favor de quienes son profesionales agrarios. Pues una de las discusiones centrales en las políticas de la tierra en Mozambique es la especulación, ante inversiones extranjeras o, por nacionales que no tienen interés en la agricultura o ganadería, e invierten por motivos ajenos a las mismas, impidiendo la continuidad de las comunidades locales en esas tierras, que las han cultivado durante décadas y que constituye el sustento de las familias que lo integran.

A partir de estas diferencias, y señalando la dificultad de acceso al crédito de los agricultores mozambicanos, que tienen derecho a usar y disfrutar la tierra, pero no a un derecho de propiedad, como derecho subjetivo absoluto, consideramos que tienen un problema de partida en lo que al acceso al crédito les afecta, pues su derecho real sobre la tierra es relativo sin posibilidad de llegar a ser absoluto.

Ambos derechos sobre la tierra, DUAT en Mozambique y propiedad en España, son derechos reales subjetivos de carácter patrimonial, y por tanto, susceptibles de valoración patrimonial, si bien, la financiación sostenida sobre un derecho temporal de posesión, posiciona al agricultor titular en una posición débil, a la hora de negociar el crédito o financiación necesaria para mejorar la rentabilidad de su explotación agraria, pues el DUAT tienen duración definida, y dicho aspecto no se desvirtúa sino que se ratifica, por el hecho de que el legislador mozambicano, de acuerdo con las conveniencias y necesidades sociales, reflejadas en el sector concreto de la agricultura y los problemas derivados de la propiedad y posesión de la tierra y de su explotación, atendiendo al interés público, ordene o no prórrogas legales de los DUAT, que experimentan modificación en su naturaleza, pues aunque como veremos se rigen por el derecho prívado, su noma constitucional es jerárquicamente superior.

\section{EL DERECHO DE PROPIEDAD DEL ESTADO SOBRE LA TIERRA EN MOZAMBIQUE}

\subsection{Antecedentes}

Durante el período colonial ${ }^{8}$, el acceso a la tierra en Mozambique fue regulado por el "Regulamento de Ocupacão e Concessão de terras nas Provincias Ultramarinas

8 Según la Constitución de la República Portuguesa, este pays corresponde al territorio continental (área de 88 500 kilómetros $\mathrm{de}^{2}$ ) y las áreas autónomas $\left(2335 \mathrm{Km}^{2}\right)$ Azores y Madeira $\left(796 \mathrm{Km}^{2}\right)$. En los otros aspectos de la geografía, la antropología y la historia, véase POLIS Enciclopedia Verbo da Sociedade e do Estado, Vol. IV, p. 1395 y s. 
(ROCT)", y en este texto legal se crearon varias categorías de usuarios de la tierra y se regularon los derechos que las personas podrían tener en materia del acceso a la tierra.

Los mozambiqueños originarios o africanos podrían ocupar tierra de forma colectiva o individual. De manera que la ocupación, el uso y usufructo colectivo de la tierra fue realizada bajo el derecho consuetudinario por las personas en las zonas rurales ${ }^{10}$, lo que no significaba la atribución del derecho de propiedad de la tierra, a pesar de que en la práctica esta se ocupara bajo un derecho consuetudinario local.

Así, la ocupación individual de la tierra, especialmente la realizada por mozambiqueños de origen portugués ${ }^{11}$, se basó en tres formas:

- El "aforamento"12;

- El "contrato de arrendamiento"13

- La "compra e venta" de tierras ocupadas por los edificios de fondo o adquiridos para la construcción, en las ciudades ${ }^{14}$.

Antes de seguir, debemos tener presente que la Ley de la tierra de 1997, en su artículo $32^{15}$, ha salvado los derechos sobre la tierra adquirida antes de la aplicación de esta ley, así el derecho adquirido a través de la ocupación o través de una solicitud oficial se mantiene como derecho adquirido.

En la historia de Portugal, ya sea antes o después de la revolución de abril de 1974, la tierra ha siempre sido de propiedad privada, aunque parte de él perteneció y continúan perteneciendo al dominio público del Estado. Si bien, la delimitación del alcance del

9 Regulación de la Ocupación y Concesión de tierra de las provincias de ultramar. Aprobado por el Decreto 43894 , 06 de septiembre de 1961. Sobre este tema, ver más desarrollo QUADROS, M. C.: "Manual de Direito da Terra", CFJJ, Maputo, 2004, p. 27. Mozambique, Angola, Cabo Verde, Guinea-Bissau, São Tomé e Principe e Timor-Leste fueron las provincias del antiguo imperio colonial portugués en el extranjero.

10 Dividido en "Regedorias", cuyo jefe se llama Regedor o Regulo.

11 A pesar de que, a partir de 1961 los mozambiqueños originarios o africanos podrían, según el ROCT obtener los derechos individuales a tierra, independientemente de la adesion a la "Assimilação", algunos mozambiqueños han beneficiado de este mecanismo del acceso a la tierra. La mayoría de los casos estaban referidos a urbanización o para proyectos de construcción en las ciudades.

12 En los viejos tiempos el arrendamiento podría considerarse también enfiteusis, prevista por el Código Civil mozambiqueña en artículos 1491 y siguientes. Esta ley establece para el desmembramiento de la propiedad en dos áreas, una directa y otra útil. El campo directo pertenece al propietario, en este caso la estado colonial y el dominio útil estaba vinculado al arrendatario, titular de un derecho del arrendatario. El arrendatario o enfiteuta podía llegar a ser propietario, mediante el pago de veinte FOROS. El concepto de foro significa el pago que debe hacer el arrendatario o enfiteuta al propietario. Enfiteusis es una de las caracteristicas de la ley de tierras, desarrollado en Asia y Europa de la edad media, y este derecho fue derogado en varios países, incluyendo la India y Portugal. En Francia, la enfiteusis puede definirse como un derecho real sobre un cuerpo del edificio (generalmente, pero no necesariamente rural) nacido de un contrato de arrendamiento a largo plazo y caracteriza por su larga duración (18 a 99 años) - ver p. Gerald CORNU "Vocabulario jurídico" Asociación Henri Capitant, cuadriga/PUF, 2001, p. 329.

13 Ver Código Civil mozambiqueño, arts.1064 y ss.

14 En las ciudades, la tierra urbanizada destinada para construción fueron vendidos a través de la venta pública o remate.

15 Artículo 32.1 (Aplicación de la ley) de la Ley de Tierra de 1997. Se dispone que "los derechos de uso y explotación de la tierra, que hayan sido adquiridos por ocupación o por aprobación administrativa, se regirán por esta ley, y quedarán protegidos". 
dominio público ${ }^{16}$ del Estado portugués ha variado con el tiempo, como sucede en otros Estados, dependiendo de la determinación expresada en la ley, en cada momento histórico, para afectar a ciertas partes de la tierra que el dominio público, o no ${ }^{17}$, atendiendo generalmente a interés general y a la función social de la propiedad de la tierra.

Los que forman la propiedad privada, su uso y explotación que, en el pasado, obedeció las disposiciones de la ley de tierras de 1850, después el régimen del Código Civil Portugués de 1867 y, actualmente, las disposiciones del Código Civil Portugués de 1966, en su libro III, con los cambios introducidos entre 1975 y hoy en día.

Por lo tanto, compartimos las conclusiones de GUNE que considera que "nunca existió en Portugal un régimen jurídico de uso y aprovechamiento de la tierra público, sino que salvo excepciones, se regula bajo la propiedad privada el uso y gestión de la tierra. Y, por tanto, como un régimen regulador de los derechos subjetivos de los individuos sobre la tierra y que se muestra en la configuración del derecho de uso y aprovechamiento de tierras previstos en la ley Mozambiqueña de tierra ${ }^{18}$.

En consecuencia, puede decirse que la experiencia portuguesa del uso y explotación de la tierra, se resume diciendo:

- salvo la parte que pertenece al dominio público del estado, la tierra es de la propiedad privada; $y$

- como propiedad privada, la tierra siempre ha sido y sigue siendo objeto de venta, hipoteca, transmisión por herencia, donación o cualquier otra forma de enajenación, por lo que, la consagración en la ley civil Portuguesa de derechos diferentes, a saber, el derecho a la propiedad, el derecho de uso y la vivienda, el derecho a la posesión, el derecho de usufructo el derecho de enfiteusis y superficie, cada uno con su propio marco legal.

De hecho, estos modelos de derechos sobre la tierra no son una particularidad, son comunes las figuras no sólo a la legislación europea en general ${ }^{19}$, y el derecho a otros países cuyos sistemas económicos se basan en la economía de mercado, como es el caso español.

Así, en España, la realidad es que la tierra y sus formas de organización se apoyan en el sistema jurídico civil bajo un régimen jurídico de Derecho privado que es el que envuelve al Derecho Agrario, a pesar de los límites establecidos como es la «función social» de la misma, a pesar de los esfuerzos de algunos autores por ubicarlo bajo el Derecho $\operatorname{administrativo~}^{20}$

16 CAETANO, M. "Manual de Direito Administrativo", 10a Edição Reimpressão, 1994, Vol. II, Almedina, p.901 y siguientes.

17 Ver GUNE, B. op. cit., pp. 17. Con quienes compartimos sus conclusiones lógicas.

18 Idem, p.18.

19 Incluso en España. El libro segundo del Código Civil español, bajo el título "De los bienes, de la propiedad y de sus modificaciones, recoge en su título primero la clasificación de los bienes, con el articulo 333 bajo el que dispone que "todas las cosas que son o pueden ser objeto de apropiación se consideran como bienes muebles o inmuebles".

20 PALMA FERNÁNDEZ, J.L.: "Hacia un Derecho Administrativo Agrario". Actualidad Administrativa, Sección Doctrina, 1999, Ref. XLVIII, pág. 821, tomo 2, Editorial LA LEY. 


\subsection{Contenido del derecho a la propiedad del estado sobre la tierra}

En la historia del Estado de Mozambique, la tierra siempre ha sido considerada básicamente como propiedad del Estado ${ }^{21}$. A grandes rasgos, este derecho de propiedad afecta a toda la tierra ${ }^{22}$ que constituye el territorio de la República de Mozambique, y en este sentido el artículo 4 de la ley de Tierras (LT) armoniza con la Constitución desarrollando su contenido, como derecho exclusivo del Estado, como único titular propietario de la tierra, excluyendo por tanto, a otras personas jurídicas privadas, pero no a las de naturaleza publica como serían las autoridades locales, quienes sí pueden ser titulares de la propiedad de la tierra. Así, las autoridades locales son los administradores de la tierra, junto a otras entidades como administradores del distrito, los gobernadores de las provincias, el Ministro de Agricultura y el Consejo de Ministros.

La administración pública, tiene un conjunto de poderes-deberes con relación al ejercicio de su titularidad sobre la tierra:

- facultades de administración (por ejemplo, respondiendo a las solicitudes de autorización de uso y disfrute de la tierra);

- poder de redistribución (por ejemplo, cuando existen límites a la extensión de terreno, se aplica la posibilidad de compartir de un particular a otro, en busca del equilibrio social y a la luz de los objetivos de justicia social y equidad);

- facultades de gestión (por ejemplo, para tomar y aplicar las medidas de protección y conservación, mientras que proporciona el uso del suelo planificado y sostenible, para determinar las condiciones de tal derecho sobre la tierra).

Cabe señalar que, en este marco, se excluye las facultades de disposición (determinar el destino de la tierra) que sólo pueden ser ejercidas por la comunidad observando las limitaciones legales, expresadas en la Constitución y la ley de tierras.

\subsection{Naturaleza jurídica de la propiedad del estado sobre la tierra}

Al tratarse de una propiedad pública, que pertenece al Estado o comunidad, gestionado y administrado directamente por su máquina política administrativa, y en consecuencia, por el derecho público: la distribución de la tierra, protección y conservación, derechos y deberes de los usuarios. Sin embargo, el derecho de uso y disfrute de la tierra se rige por derecho privado.

De tal manera, que hay que tener especial cuidado a la hora de aplicar el régimen jurídico, que variará según nos encontremos ante el primer caso o en el segundo, donde se manejan las relaciones que se establecen a nivel de individuos, sin importar que el Estado sea un agente participante, porque esto es a través de algunas de sus instituciones, como titular de una parcela de tierra, en su relación con los demás usuarios y, por tanto, se considera regulado por el derecho privado.

21 José Pedro Fernándes, Dicionário Jurídico da Administração bens do domínio publico. Público, pág. 166, volume IV, Lisboa 1991.

22 Toda la tierra no es en el sentido legal, pero cada parte delimitada en la tierra se considera algo, en este caso por ejemplo el territorio de un estado o parcelas de tierra en la posesión de un particular. 
Así, los conflictos que pudieran surgir de estas ultimas relaciones jurídicas que afectan al derecho de uso y disfrute, se resolverán por los tribunales civiles, mientras que la primera, referida a la titularidad del Estado, serán competencia de los Tribunales Administrativos. De ahí que, defendamos que el derecho de uso y disfrute de la tierra tiene su propia naturaleza jurídica, independientemente de que se encuentre en manos de varios propietarios o de una comunidad local ${ }^{23}$, si bien con las limitaciones de transmisión establecidas como prohibiciones en la Ley de tierras bajo el apoyo constitucional de la Constitución mozambicana (art. 46 ff).

Atendiendo a lo expuesto, el contenido y la naturaleza de la propiedad del Estado sobre la tierra, diferencia entre derecho propiedad estatal sobre la tierra y el DUAT (derecho de uso y disfrute) según los actores o sujetos que intervengan:

- El primero cuando la comunidad publica es titular de la propiedad de la tierra. Termina la expresión legal diciendo que la tierra es propiedad del Estado. El preámbulo de la ley del suelo de 1979, en el § 3, el fue muy explícito acerca de que: "cuando se dice que la tierra es propiedad del Estado, esto significa que la tierra pertenece a los ciudadanos con nacionalidad de Mozambique."

Estamos hablando que, cada uno de los ciudadanos que, constituyen la comunidad nacional de Mozambique, sobre el cual recae el derecho referido y se ejerce en dos momentos diferentes. Al principio a través de los poderes de disposición, determinando el destino de la tierra, estableciendo cómo cada miembro de la comunidad (sociedad) disfrutarán de la tierra y, la imposición de limitaciones en ese mismo disfrute. La manera de hacerlo es, por supuesto, a través de la institución del marco jurídico correspondiente, en el que, materialmente, cada uno de los ciudadanos forma parte, y la misma se realiza a través de las autoridades políticas; quienes ejercen por delegación las competencias de la administración, en el ejercicio de su poder soberano. Es, en este caso, cuando el poder ejecutivo de la comunidad, como administración pública, se encarga de cuidar de la administración y gestión diaria de la tierra.

- La segunda parte es porque la administración pública, a quien se atribuye, entre otras cosas, las facultades para otorgar tierras, así como para reconocer los derechos, ya adquirieron por otros medios las tierras legítimamente y disponen por tanto de ellas.

- La tercera parte es, otra vez, cada uno de los ciudadanos mozambiqueños y, extensivamente, persona jurídica tenga el ejercicio del derecho de uso y disfrute de la tierra.

En la interpretación de esta importante disposición legislativa hay que distinguir, por tanto, cuando viene al Estado, en el sentido de comunidad o Estado como ente administrativo, con poderes de propietario, o con poderes de administrador, en el segundo caso.

23 Y en medida cada uno si es autónomo como un bien, una cosa que es objeto de un derecho subjetivo de los usuarios de la tierra. 
Debemos, en nuestra opinión, todavía conocer la dualidad de la materia de la tierra que ocupa el ciudadano, particularmente, en el marco legal. Al principio, como propietario de la tierra, porque parte del Estado es la comunidad-Estado y, en segundo lugar, como sujeto del derecho de uso y disfrute de la tierra.

Es cierto que, en España, la propiedad agraria es esencialmente posesiva pues conlleva la realización de una actividad productiva, y que se regula la posesión mediata o inmediata bajo el articulo 463 del Código civil, de manera que es posible la transmisión de diferentes derechos de posesión sobre un mismo bien inmueble, siempre que se puedan ejercitar por sus titulares atendiendo a la función social, económica y ambiental que tiene la tierra y, por ende, su explotación agraria. Y esto es posible, porque la Constitución española reconoce un derecho a la propiedad privada que se configura y protege las facultades individuales sobre las cosas, que paralelamente, se acompañan por los deberes y obligaciones establecidos, de acuerdo con las leyes, en atención a valores o intereses de la comunidad, es decir, a la finalidad o utilidad social que cada categoría de bienes objeto de dominio esté llamada a cumplir ${ }^{24}$.

\section{ANÁLISIS COMPARADO CON OTROS PAÍSES DEL RÉGIMEN JURÍDICO DE LA TIERRA AGRARIA}

La tierra es un medio universal para la creación de riqueza, de ahí que todos los países desarrollen un marco legal para el acceso y uso de la tierra, ajustado a su realidad social y económica, que va modificándose, atendiendo a las exigencias que el sector demanda.

Mozambique como tantos otros países, considera que la tierra es el medio más importante de la producción y la creación de riqueza, calificadas como propiedad pública del Estado, si bien un sector doctrinal al que pertenece BOAVENTURA GUNE especifica la necesidad de "declarar la tierra a nivel de la Constitución como propiedad del Estado y a nivel de ley ordinaria, determinar las condiciones de su acceso y uso, a través de la consagración de la figura del derecho de uso y el uso de la tierra" ${ }^{25}$.

La delimitación del contenido y los límites de esta figura en Mozambique, implican un análisis previo de experiencia extranjera, que influenciaran el régimen de uso y el aprovechamiento de la tierra, por lo que conforman el entorno histórico e ideológico, para compararlos con nuestra experiencia para entender las influencias.

Si tomamos las sugerencias de BOAVENTURA GUNE ${ }^{26}$ los adecuados criterios de selección del país cuyo derecho ha afectado a la de Mozambique, son tres:

- El criterio de proximidad histórica-cultural, con países con una historia común en Mozambique, situado fuera del continente africano y asociado con el

24 RODRÍGUEZ DE SANTIAGO, J. M.: “Artículo 33 CE: Derecho a la propiedad privada y a la herencia". Diario La Ley, 25 de Mayo de 2018, WOLTERS KLUWER. Vid. (SSTC 37/1987, de 26 de marzo, FJ 2, y 89/1994, de 17 de abril, FJ 4.

25 GUNE, B. "Da natureza juridica do direito de uso e aproveitamento da terra em Mozambique", Tesis de maestría, Faculdade de Direito-Universidade Eduardo Mondlane, Maputo, 2006, pág. 12.

26 GUNE, B. op. cit., p. 13. 
Romano-Germánico, como parte del sistema de Mozambique. Esto conduce a seleccionar la de Portugal con una afinidad lingüística e histórica;

- El criterio de vecindad y proximidad del camino en la lucha por la liberación, donde la elección de Angola;

- El criterio de las fuentes de inspiración política e ideológica en la creación del derecho de uso y el aprovechamiento de la tierra, que se requiere para mantener el bloque chino-soviético siempre eliminó la propiedad privada de la tierra durante las revoluciones en cada uno de sus países.

\subsection{Formas de uso y aprovechamiento de la tierra en timor-leste como colonia Portuguesa}

Timor Oriental fue posesión portuguesa de 1512 hasta el 28 de noviembre de 1975, FRETILIN declaró la independencia de este país, tras la decisión de Portugal de retirarse del territorio.

Sin embargo, inmediatamente, el 07 de diciembre de 1975, el país sufrió una invasión extranjera, liderada por Indonesia, una ocupación que se mantuvo hasta 1999, cuando el país entró a la administración de las Naciones Unidas, el reconocimiento internacional del estado Maubere, 20 de mayo de 2002.

En este período entre 1512 y 1975, la tierra estaba sujeta a dos regímenes de uso y disfrute de la tierra, uno referido a tierras de dominio público por el Estado, otra sobre el régimen privado de las tierras que eran propiedad de los individuos.

Como en otros Estados, el dominio público del Estado compuesto por entonces los bienes fuera del comercio legal, es decir, que no podía ser objetos de privado de derechos, entre otras cosas, caminos, playas, lagunas, arroyos y sus respectivas camas, los recursos minerales del subsuelo, los ferrocarriles, aeropuertos y aeródromos. Mientras que el dominio privado del Estado estaba compuesto por los terrenos del propio Estado quien cedía en propiedad tierras o estas eran adquiridas por compraventa o por cualquier otra forma de adquisición del dominio a particulares.

En el período de la ocupación por Indonesia, el dominio público perteneció al Estado indonesio quien revertía las tierras privadas preferentemente y de manera mayoritaria en favor de los hacendados o agricultores indonesios, en detrimento de los ciudadanos timorenses o mauberes. Situación que se agravó, cuando el catastro nacional donde se recogían los derechos de uso y titularidades se destruyó durante la ocupación de Indonesia, donde además el terrorismo organizado destruyó la estructura de la administración pública del país. Lo que provocó que propiedades de ciudadanos desaparecidos en el exterior y extranjeros, también fueran ocupadas bajo apropiación indebida e ilegalmente.

Posteriormente, ya durante el período de la administración de la UNTAET $^{27}$, se han adoptado varias medidas temporales relativas a los bienes inmuebles, tales como la

27 UNTAET significa Organização das Nações Unidas para a Administração Transitória em Timor-Leste, in www.jsmp.minihub.org/Legislation/Terras\%2520PORTUGUESE\%2520Version\%2520of\% 
congelación de la situación jurídica de determinados bienes. Si bien, la UNTAET no ha sabido darle soluciones adecuadas ante la falta de un registro como era el catastro nacional que ampare y respalde sus decisiones desde la seguridad jurídica.

Actualmente, Timor-Leste tiene reconocida internacionalmente la independencia del territorio, una nueva Constitución de $2002^{28}$, cuyo artículo 54 regula los principios generales relativos a la propiedad privada, reconociendo inequívocamente este derecho, si bien delimitado que debe tener una función social. Lo que demuestra que a pesar de la influencia cultural e histórica de otros países su camino ha sido diferente al de Mozambique.

Así, su Constitución determina que sólo los ciudadanos nacionales tienen el derecho a la propiedad privada de la tierra, sino que ha calificado de delito la apropiación indebida de activos, ya sea bienes muebles o inmuebles que se hayan producido en el pasado.

Sin embargo, esta disposición constitucional según la cual sólo los timorenses pueden adquirir la propiedad de la tierra, tiene como objetivo evitar que los extranjeros y particularmente los indonesios podría adquirir título a la tierra en Timor Oriental. Por lo tanto, lo consideramos un instrumento legal para garantizar la defensa de la tierra a favor de sus ciudadanos.Su texto constitucional regula la organización económica y paralelamente el uso y aprovechamiento de la tierra:

- Existe un dominio público del Estado, que comprende toda la tierra fuera del comercio jurídico, que son los que, no puede ser objetos de derechos privados, entre otras cosas, caminos, playas, lagunas, arroyos y sus respectivas camas, los recursos minerales del subsuelo y terrenos reservados para la construcción de infraestructura pública, incluyendo cualesquiera otras que eran propiedad del Estado portugués en 07 de diciembre de 1975.

- Es un dominio privado del Estado, que comprende todas las tierras que pueden darse o venta por parte del Estado de Timor; y

- Existe un dominio particular o privado, comprendiendo, las tierras son propiedad privada de los individuos.

Así, mientras las tierras de dominio público del Estado están reservadas para el uso del mismo atendiendo al interés público, para el funcionamiento de sus instituciones y la construcción de infraestructuras de interés general, el dominio privado se traslada fundamentalmente bajo venta y arrendamiento, de manera que se permite la hipoteca de la propiedad como forma de acceso al crédito entre otras figuras, y cualquier otra forma de disposición, configurando así un marco jurídico de propiedad privada de la tierra bajo el régimen de derecho privado.

En consecuencia, no existe en la actualidad en Timor-Leste, una figura del derecho de uso y aprovechamiento de la tierra similar al que existe en Mozambique, por el contra-

2520Final $\% 2520$ Law $\% 2520$ Project $\% 2520$ (XG\%2520comments).pdf + Lei + de + Terras + de + Timor + Leste $\&$ hl=ptBR. Conultado el día 24 de Enero de 2017.

28 Constituição da República Democrática de Timor-Leste, aprobada en el dia 22 de Marzo de 2002. 
rio, sí existe, tal y como hemos manifestado, la propiedad privada de la tierra y con ella sus derechos y facultades de libre disposición.

\subsection{Formas de uso y aprovechamiento de la tierra en Sudáfrica}

El proceso de expropiación de tierras a los naturales en Sudáfrica ${ }^{29}$ comenzó con la llegada de Jana Van Riebeeck a la playa de cabo de buena esperanza en 1652, como primer administrador colonial, pero ganó una particular intensidad y extensión con el establecimiento del sistema de segregación racial denominado apartheid ${ }^{30}$.

La formación de la llamada Unión de Sudáfrica en 1910 representó la consolidación de la derrota militar de los reinos locales y la legalización de la minoría blanca, conformada por ciudadanos británicos y neerlandeses. A esto siguió la aprobación de la ley de tierras ${ }^{31}$ que legitima la toma de tierra por esta minoría blanca, que consistía en reservar la mayor parte del territorio de Sudáfrica a la propiedad exclusiva de esta minoría. A través de esta ley y otros contenidos racistas, millones sudafricanos fueron removidos de sus tierras y sus casas fueron asolado.

En el período posterior a la segunda guerra mundial, segun WELLIGTON THWALA, "aunque representan menos del $80 \%$ de la población, los africanos fueron confinados en sólo el $13 \%$ de la tierra de su patria, convertirse en reservados $87 \%$ de la tierra en el país para la minoría blanca, de origen anglo-boer ${ }^{32}$.

En este contexto, la Constitución Sudafricana llegó precedida de diferentes leyes ${ }^{33}$, que contenía compromisos del Estado hacia los campesinos sin

29 La República de Sudáfrica se encuentra en África Meridional y limita con Namibia, (920km), Botswana (1554 $\mathrm{km})$, Zimbabwe $(250 \mathrm{~km})$, Mozambique $(480 \mathrm{~km})$ y Swazilandia $(450 \mathrm{~km})$. Está bañada por el océano en su costa occidental y el Océano Índico en su parte oriental.

30 Apartheid es el sistema político que funcionó en Sudáfrica de 1913 a 1994, consistente en la segregación racial en todos los ámbitos de la vida social. A pesar de que esta segregación racial inició en 1658, cuando el Khoi fueron informados podría no más habitan en los territorios de la sal y el Liesbeck, su institucionalización fue de 1913.

31 La Ley de las tierras indígenas, fue aprobada en 1913. Esta ley restringió el área reservada a la ocupación de los nativos africanos, separado de los inquilinos de sus tierras y reemplazar los acuerdos de arrendamiento para otros trabajos. La aprobación de esta ley en 1913, representó un sufrimiento indescriptible a muchas generaciones de personas de la raza negra.

32 Cfr. WELLIGTON D, THWALA, Experiência sul-africana na reforma agrária, in www.landaction.org/gallery/ South\%20African\%20Land\%20Reform-Portuguese.pdf. Consultado el dia 24 de Enero de 2017.

33 Elenco de leyes:

- La ley de la tierra y desarrollo confiable, aprobada en 1936, que dio a los blancos las tierras hasta ahora reservadas a los negros, haciendo la ocupación ilegal por estos últimos.

- Las leyes nativas enmienda, adoptada en 1937, que llegó a prohibir la compra de lotes en centros urbanos de los negros.

- La ley de áreas del grupo, adoptado en 1950, que estableció la discriminación racial en las áreas de negocio.

- El acto Bantu de las autoridades, aprobada en 1951, que permitió el establecimiento de las autoridades tribales, regionales y territoriales.

- Ley de prevención de robo, también adoptado en 1951, que permitió al Gobierno a crear campos para el reasentamiento de las poblaciones de las granjas de los blancos;

- El reasentamiento ley aprobada en 1954, negro, que permitió el retiro de los negros de algunas zonas a otras según la política de segregación racial y bantustonização del país.

- La ley de promoción de autonomía, aprobado en 1959 Bantu, que crearon los bantustanes y determinó que cada uno de ellos sería habitado por su territorio natural.

- La modificación de las leyes y la ley de la confianza, ambos adoptados en 1964, que juntos han abolido la posesión y la ocupación de la tierra por el trabajo de las granjas. 
tierra $^{34}$, con la responsabilidad de hacer todo lo posible para la redistribución de la tierra, a través del refuerzo de determinados compromisos ${ }^{35}$.

Con la Constitución, llegó, a posteriori, la reforma agraria en Sudáfrica hacia la propiedad privada de la tierra. Tal reforma, supone uno de los principales retos la implementación de la reforma agraria, a través de los procesos de restitución y redistribución, transferencia de la tierra a los hasta ahora desfavorecidos, esto es, debido a la redistribución de la tierra es una condición sine-qua-non para el éxito de la lucha contra la pobreza, se desarrolló desde tres direcciones:

- Restaurar la propiedad de la tierra de cada sudafricano, perdido como consecuencia de la segregación racial o compensar esto o su heredero, la pérdida de esta tierra;

- Asegurar, que los pobres y desposeídos tenían acceso a la tierra para ella vivir y producir los alimentos;

- Garantizar la distribución racional de la tierra, para apoyar los esfuerzos de crecimiento económico y reducción de la pobreza.

Para llevar a cabo esta reforma, el país adoptó la plantilla que se denomina mecanismo de mercado, que es usar las fuerzas para redistribuir la tierra basada en los principios de la venta voluntaria, aunque con cierto apoyo del Estado. En este contexto, el Estado proporciona subvenciones para adquisición de terrenos y financiación de la organización y la planificación necesaria para la compra y posesión de estas tierras, ya sea por individuos o familias, o por las comunidades.

Este modelo de reforma agraria se basa en la eficiencia, como la racionalidad del mercado de tierras busca eficiencia en el sector agrícola, con el fin de aumentar no sólo la producción y la productividad del país, sino también la confianza de autosuficiencia y de los inversores de alimentos.

- La pérdida de tierras había producido, entre otras cosas, esto para los africanos, la escasez de vivienda, la falta de seguridad, inestabilidad familiar, migración, degradación de la tierra, además de severas limitaciones para las actividades agrícolas y agroindustriales.

34 Directrices constitucionales:

- "El estado debe tomar medidas legislativas razonables y otras medidas, las naturalezas dentro de sus recursos disponibles, con el fin de estimular las condiciones que permiten que los ciudadanos tengan acceso a la tierra de manera equitativa";

- "Una persona o comunidad cuyas tierras legalmente está amenazada como resultado de las leyes raciales discriminatorias o prácticas pasadas lleva, en la medida proporcionada por un acto del Parlamento, a legalmente asegurado o reparar comparable"; y

- "Una persona o comunidad desposeída de su propiedad después de 19 de junio de 1913 como resultado de las leyes raciales discriminatorias o prácticas se denomina, en la medida proporcionada por un acto del Parlamento, la restitución de esa propiedad o equivalente."

35 Tales compromisos son:

- Redistribuir la tierra cultivable;

- Completar el proceso judicial de las solicitudes de restitución de tierras;

- Llevar a cabo una reforma agraria que modifique las relaciones sociales y económicas resultantes del anterior sistema de distribución de la tierra;

- Reducir la pobreza mediante el aumento de la producción y distribución de la riqueza;

- Desarrollar de la economía a través de una reforma global del sistema agroindustrial;

- Asegurar, de que la tierra a cada uno y a todos los sudafricanos. 
Con la implementación de este modelo, se lograron algunos avances, aunque muy por debajo de la prevista. Por ejemplo:

- Desde 1994, el Gobierno ha construido más de 1 millón de casas para los pobres, sobre todo negros,

- El Estado dio a personas las viviendas que pago alquiler hace muchos años y cuya compra fue rechazada porque tales casas eran en supuesto "blanco Sudáfrica".

- Al mismo tiempo se concedieron a muchas otras personas, para los mismos derechos de propiedad del Estado en lugares donde nacieron y trabajaron toda su vida.

Así, la reforma agraria que se lleva a cabo en África del sur se dirige para entregar el título más natural a la tierra durante siglos perteneció a una minoría.

La recuperación de los terrenos se apoya sobre estructuras tanto comunales como individuales, lo que a nuestro entender es un factor decisivo en la lucha contra la pobreza, pues la tierra es un recurso escaso sujeto a varios tipos de uso como la producción agrícola, vivienda, urbanización, construcción de carreteras, puentes, presas y otras infraestructuras de interés público.

En el mundo de recursos escasos, la consecuencia lógica es la lucha por la propiedad de lo poco que hay, de modo que la preocupación del gobierno en la distribución de la tierra ${ }^{36}$ y luego redimensionar su caso también la lucha del pueblo de la tierra.

Si bien la reforma de la tierra evoluciona lentamente, lo cierto es que una vez logrado este objetivo de restitución y redistribución, cada trabajador de la tierra se convirtió en propietario de una fracción de la misma, lo que permitió el nacimiento del derecho a la propiedad privada, y en consecuencia permite el ejercicio de otros derechos además del subjetivo derecho de propiedad como son los derechos reales de usufructo, uso y habitación y el derecho de superficie en la medida que tales trabajadores, ya dueños de la tierra, puede utilizar, cosa o deshacerse de él, así como otros derechos obligacionales como son el arrendamiento o la aparcería.

Reforma agraria todavía está en el orden del día en este país, en la medida en que gran parte de la tierra permanece bajo propiedad de la minoría blanca, porque el mercado ha estado fallando.

La cuestión de la tierra en África del Sur aún no se resuelve en este momento y reforma agraria sólo puede resolver, modificar el marco de las relaciones sociales y económicas que prevalece en las zonas rurales. De ahí que entendamos que la tierra debe distribuirse entre quienes deseen cultivarla o llevar a cabo cualquier otro tipo de aprovechamiento. Se trata por tanto de abordar reformas económicas, así como políticas y sociales acordes con su realidad.

36 “A finales de 2001, menos del 2\% de la tierra habían sido transferido a la población negra, a través del programa de reforma agraria. Leyes que esperaban asegurar mejor la tierra pero que no han sido tan eficaces como se esperaba, pues de las 68.878 peticiones recibidas para restitución de tierras, 12.678 sólo se juzgaba. Si bien hay que destacar que de ello se han beneficiado 40.000 hogares predominantemente urbanos, de los cuales sobre $40 \%$ recibido en compensación en lugar de la recuperación de la tierra. La redistribución de la tierra transfiere menos de la mitad 1 millón hectáreas a familias 45.454 (480.400) hasta marzo de 1999, que fue de la meta establecida previamente de 25,500,000 hectáreas de cultivo “. 
En cuanto al uso y disfrute del programa en África del sur, esto obedeció siempre el modelo de economía de mercado, la tierra se comporta de una zona reservada para el Estado y, otros bienes dominio público que, no son objeto del comercio, ya que pertenecen al dominio privado del Estado. Al mismo tiempo, siempre ha habido una tercera zona, la mayoría, que es de propiedad privada y en la que caen, dependiendo de la situación concreta, diversos derechos.

La experiencia del africano del sur del uso y explotación de los enfoques de tierra siguiendo modelos occidentales apoyados en la propiedad privada de la tierra, si bien, debemos destacar que comporta una zona de dominio público del Estado que no es objeto de apropiación privada, y que a diferencia de esta que se puede ceder o vender, a quien la quiere o puede pagar, la propiedad publica no. En consecuencia, no hay similitud hoy en día, entre el régimen jurídico de la tierra y su apropiación en África del sur, ni tampoco una regulación parecida respecto a los derechos de uso y disfrute de la tierra similar al existente en Mozambique, a pesar de ser un país limítrofe con el nuestro.

\section{EL DUAT EN EL DERECHO RURAL MOZAMBICANO}

En Mozambique, como ya hemos puesto de manifiesto, no existe la propiedad privada de la tierra rústica, de tal manera que la tierra y sus recursos asociados son propiedad del Estado. Sin embargo, con la llegada de la Ley de Tierras, se otorgó a los particulares el derecho a usar y beneficiarse de la tierra y esto se reconoce como DUAT. Aunque el terreno en sí, no puede ser vendido, hipotecado o enajenado; lo cierto es que los edificios, las infraestructuras y las mejoras construidas en el terreno si pueden ser hipotecados y vendidos.

Esto ha supuesto un avance en el desarrollo del país, pues las entidades extranjeras pueden ser titulares de un DUAT mediante solicitud a los Servicios Geográficos y Catastrales si así lo solicitan, siempre que el solicitante corporativo esté establecido o registrado en Mozambique; o si se trata de una persona física quien lo solicita, esta haya residido en Mozambique durante al menos cinco años.

Por ello, la doctrina de Mozambique propone los DUAT como un derecho real. Son varios los autores ${ }^{37}$ que, han intentado proponer la definición de derecho real, entre ellos OLIVEIRA ASCENSAO, quien los define como "derechos absolutos, relacionados con una cosa y orientados a la asignación, en el interés del sujeto"38. RUI PINTO establece la ley de la propiedad (en el sentido objetivo) como "una situación jurídica activa que afectará a los bienes, de manera asociada a los intereses de una persona"39. Bajo la ley mozambiqueña, el régimen jurídico de los bienes están regulados por su Código civil en los artículos 1251 y siguientes ${ }^{40}$.

37 PINTO, R. "Direitos Reais de Moçambique”, ICJ-FDUL, Almedina, Coimbra, 2006, p. 13 y ss., y ASCENSÃO, J. "Direito Civil - Reais", Coimbra Editora, 1993, pp. 44 y ss.

38 ASCENSÃO, J. «Direito Civil ..., op. cit. Pp.55 y ss.

39 PINTO, R., op. cit., p. 13.

40 El Libro segundo del Código Civil español, bajo el título «De los bienes, de la propiedad y de sus modificaciones», recoge en su Título primero la clasificación de los bienes, con el art. 333 (LA LEY 1/1889) bajo el que dispone que todas las cosas que son o pueden ser objeto de apropiación se consideran como bienes muebles o inmuebles 
Independientemente de la elección y excluyendo la formalidad junto con el carácter absoluto del derecho a la propiedad, son cinco los caracteres ${ }^{41}$ que se consideran los más importantes en esta definición donde se incluye:

- Incidencia (directa o no) del derecho a una cosa;

- La existencia de una posición activa del titular de un derecho;

- La existencia de un enlace, legal o de facto, entre el titular y la cosa;

- La protección especial de la posición active frente a terceros;

- La existencia de posiciones pasivas de sus respectivos titulares.

De hecho, nuestro objetivo es afrontar esos cinco elementos a la DUAT desarrollándolos a continuación.

\subsection{Caracteristicas y acciones de protección de los DUAT}

\section{A. La incidencia directa del derecho sobre una cosa}

El DUAT se basa en la tierra, según artículo 1, n. ${ }^{\circ} 2$ de la Ley de la Tierra en 1997, específicamente en un terreno específico que será delimitado y separado del Fondo Nacional de las tierras. Y bajo este derecho se da al usuario el ejercicio de un derecho seguro, renovable y a largo plazo que cubre un período de hasta 50 años. Algunos por ello lo comparan con un contrato de arrendamiento, pero a nuestro entender se equivocan porque se asemeja mas a la concesión administrativa basada en un contenido de derechos y obligaciones entre el Estado y el usuario; y donde la Ley proporciona a las comunidades y a la población local un título "de propiedad de uso temporal" de la tierra seguro, al tiempo que proporciona seguridad a los inversores.

Así, una vez que una persona jurídica o física es autorizada o reconocida por el DUAT, debe explotar la tierra y a veces en relación con el Estado, la familia o la comunidad local. Este último tema a menudo desempeña el papel de organismo de control, ya que los que se pretende es garantizar el uso adecuado de la tierra.

\section{B. La existencia de una posición activa del titular del derecho}

El titular del DUAT tiene todos los poderes establecidos en la ley, sobre todo el poder del uso y goce y difrute de la tierra, específicamente la libertad de construir y mantener los edificios, mejoras de arrendamiento en la tierra, etc. Pero también la posibilidad de transmisión ${ }^{42}$ de DUAT, a través de la transferencia del fondo de la tierra o de la construcción o construcciones llevadas a cabo en la finca.

En este sentido la disposición básica de la Ley de Tierras establece que "la tierra es propiedad del Estado y no puede ser vendida ni enajenada, hipotecada o gravada de otro modo". Sin embargo, el DUAT, puede ser vendido, enajenado o gravado de otra manera, pues lo que se transfiere son los derechos de uso con sus limitaciones, lo que dentro del

41 Idem, pp. 57-58. PINTO, R. añade publicidad y la secuela, también afirma que la tipicidad no es esencial para el derecho real. Los cinco caracteres se pueden encontrar también en: QUADROS, M. op. cit, p.41.

42 Según los limites que se dispone em el articulo 16 de la LT - 1997. 
la restricción existente sobre la propiedad agraria en Mozambique es un pequeño margen que da entrada a la la creación de empresas conjuntas entre empresas comerciales y agricultores familiares, donde cabe la negociación entre los titulares de derechos previamente adquiridos de usos y nuevas inversiones que tienen entre sus objetivos el acceso a los derechos de uso de la tierra. Estas relaciones son a nuestro entender contractuales y nacen cuando un DUAT puede ser negociado, utilizando un poder irrevocable emitido por el "vendedor" y dirigido al "comprador". De acuerdo con la Ley de Tierras, un DUAT puede adquirirse de tres maneras:

- Ocupación de la comunidad local regida por el derecho consuetudinario;

- Ocupación de buena fe, después de usar la tierra durante al menos 10 años sin objeción; y

- Adjudicación y asignación de un contrato de arrendamiento de 50 años por parte del Estado.

El titular de la DUAT finalmente tiene el poder para defenderse contra quienes practican actos que atentan contra estos derechos. Así que puede utilizar la acción directa ${ }^{43}$ como instrumento judicial en protección de sus derechos.

\subsection{La posesión de hecho y de derecho}

El enlace puede ser causado por la posesión, con título o sin título. Esta realidad se manifiesta varias veces por los actos materiales de la ocupación de la tierra, una situación reconocida por el CRM de 2004, artículo 111 y también por la ley del suelo de 1997, artículo 12, como una forma de adquisición de la DUAT.

El vínculo jurídico o de derecho resulta de la existencia de un título, por ejemplo, el acto administrativo que autoriza el DUAT. Aquí, estamos hablando de la existencia de un acto constitutivo de autorización del DUAT, que se traduce en un título de DUAT, Ley de la tierra permite la existencia de un título provisorio o definitivo del DUAT ${ }^{44}$.

\subsection{Protección de la posición activa contra terceros}

El titular del DUAT puede hacer uso de los medios de protección de la propiedad y posesión, máximo por llamada a la acción de reclamación, regulado por el Código Civil mozambiqueño (CCM), en el artículo $1311^{45}$.

Una vez que es aplicable a todos los derechos de propiedad y sabiendo que el DUAT se basa en la tierra, es lógico concluir que el régimen jurídico de acción y reivindicación ${ }^{46}$, con los cambios necesarios, es aplicable a los titulares del DUAT frente a posibles perturbaciones en el ejercicio del derecho de uso.

43 Véase el artículo 13, apartado a) del Decreto del Consejo de Ministros n ${ }^{\circ} 66 / 98$, que aprueba el Reglamento de la Ley de la Tierra en 1997.

44 Artículos 25 y 26 del LT-1997 y artículos 28, 29 y 36 del RLT - 1998.

45 Acción de reclamación: «El propietario puede requerir legalmente de cualquier poseedor o mero poseedor de la cosa el reconocimiento de su derecho a la propiedad y el consiguiente reembolso de lo que le pertenece».

46 Vid. CHIZIANE, E. "Lei de Terra entre a Lei e as praticas na defesa de direitos sobre a terra" in MANDAMULE, U (Coordenação). "Terra, Poder e Desenvolvimento em Moçambique”, Escolar Editora, Maput, 2017, pp. 56 y ss. 


\subsection{La existencia de posiciones pasivas que pertenecen a los no titulares del derecho}

Situaciones activas de los titulares de un derecho tienen como contra partida la existencia de posiciones pasivas sujeto a los no titulares del derecho. Aquí, el ordenamiento jurídico impone a terceros o a otros miembros de la sociedad, el deber de no perturbar el derecho legítimamente autorizado o reconocido a una persona.

Sin embargo, existen algunos problemas respecto a la titularidad del uso y su transmisión ${ }^{47}$, como son la falta de claridad por parte de algunos funcionarios de la administración del gobierno que en ocasiones realizan interpretaciones arbitrarias de la ley que derivan en una merma del principio referido a la "ocupación de buena fe de la tierra" bajo el que se confiere derechos legales de propiedad y que como ya hemos expuesto es fundamento de la Ley.

Otro problema que consideramos hay que señalar es la falta de capacidad, pues ni las comunidades ni el gobierno tienen la capacidad de garantizar consultas comunitarias adecuadas antes de otorgar derechos de uso a los inversionistas, a pesar de existir directrices para ello

Finalmente, entendemos que es también un problema la asignación gratuita de los DUAT unido a la inexistencia de impuestos recaudatorios sobre la tierra. Pues el resultado final es que se ha fomentado el acaparamiento extensivo de tierras, cuando esto no era ni la finalidad ni el objetivo de la transmisión y constitución de los DUAT.

\section{FACULTADES DEL TITULAR DEL DUAT}

El contenido de un derecho de propiedad puede ser analizado según las facultades y prerrogativas legales otorgados a un sujeto ante una determinada cosa. En el caso del derecho a la propiedad, dichos poderes se expresan completamente, sin embargo, algunas limitaciones son necesarias por razones públicas o legales.

Sabiendo que las facultades de uso, disfrute y disposición representan el paradigma de los derechos de propiedad, analizaremos si estos paradigmas se manifiestan en el DUAT. Así, la Ley de tierras de 1997 y el Reglamento de la Ley de tierra (RLT) de $1998^{48}$ indican los más importantes poderes del titular de un DUAT, que incluyen los siguientes:

- Usar la tierra cuya la posesión fue reconocida o autorizada sobre el DUAT, según el articulo 13 del RLT-1998.

Los medios jurídicos del derecho privado de la defensa de una cosa, terra, incluyen las medidas o providencias cautelas, las acciones de posesión, acciones de prevención, las acciones personales y las acciones reales.

47 DURANG, T. AND TANNER, C.: “Access to Land and Other Resources for Local Communities in Mozambique: Current Examples from Manica Province", Paper Presented to the Green Agri Net Conference on Land Administration in Practice, Denmark, April 1-2, 2004.

48 Orden del Consejo de Ministros n 66/98, 08 de diciembre, que aprueba el Reglamento de la Ley de la tierra (RLT), publicado en el Boletim da República, serie I, Suplemento n. ${ }^{\circ} 8$ (3), 08 de diciembre de 1998. 
- Acceso a la parcela y utilizar, para poder acceder a otros recursos existentes en el dominio o en las propiedades vecinas, como las fuentes de agua públicas, creación de servidumbres convencionales, artículo 13, apartado b) del RLT-1998.

- Se defiende contra las violaciones de los demás, el artículo 13, párrafo) del RLT-1998.

- Transmitir, a través de la herencia, la poseción de la tierra y los derechos que están asociados segundo el artículo 16, n¹ de la LT-1997;

- Transmitir la posesión de la tierra y los derechos asociados a él, a través de la transmisión de los edificios incorporados a la tierra, según el artículo $16, n .^{\circ} 4$ de la LT-1997;

- El poder de transmitir las mejoras hechas en la tierra, que tenemos el DUAT, o incluso el artículo 16, ${ }^{\circ}{ }^{\circ} 2$ de la LT-1997 y el artículo 15 del RLT -1998;

- La autoridad para establecer una hipoteca sobre bienes raíces, una vez la autorización definitiva de DUAT, conformidad con el artículo 13, Nº 1 de la RLT-1998; y

- Utilizar el título de aprobación provisional del DUAT, con el fin de motivar las solicitudes de financiación de los bancos, en conformidad con el artículo 13, $\mathrm{n}^{\circ} 2$ de la RLT- $1998^{49}$.

Después de presentar brevemente las facultades del titular de un DUAT, parece justo decir que el titular de este derecho tiene el poder para uso y disfrute. El poder de disposición queda excluido de los poderes otorgados al titular de un DUAT.

\section{LA NATURALEZA JURÍDICA DEL DUAT Y SU RELACIÓN CON OTROS DERECHOS REALES}

El DUAT es un instrumento clave en el análisis del régimen jurídico de la tierra en Mozambique si bien su naturaleza jurídica es cuestionada, por entender algunos que su regulación debe llevarse a cabo bajo las normas de derecho público, mientras que otros abogan porque se desarrolle bajo el derecho privado, partiendo en ambos casos de que lo más importante es situar el DUAT en el marco del Derecho, como se menciona en las constituciones de 1975, 1990 y más recientemente de 2004. Este instrumento, el DUAT, se desarrolla también en la Ley de Tierras de $1979^{50}$ y actualmente, en la Ley de Tierras de $1997^{51}$.

49 De hecho, el artículo 13, $\mathrm{n}^{\circ} 2$ de RLT - 1998 dispone que "los solicitantes o titulares de la DUAT pueden presentar el título o el certificado provisional a organismos financieros, en el contexto de la solicitud de crédito. Esto no significa que la tierra en sí misma puede ser objeto de una garantía bancaria.

50 La Ley n. ${ }^{\circ} 6 / 79$, de 03 julio.

51 Los artículos $1, \mathrm{n} .{ }^{\circ} 2$ y 2 de la LT- 1997. 
Varios autores cuestionan la naturaleza jurídica del DUAT, como RUI PINTO ${ }^{52}$, MARIA QUADROS ${ }^{53}$, BOAVENTURA GUNE ${ }^{54}$ y ANDRÉ CALENGO ${ }^{55}$. Este debate es importante porque se trata en el mismo tiempo determinar si el DUAT es parte de los derechos reales o determinar si él debe incorporarse en el derecho privado o público.

A partir de esto vamos a analizar los bienes clasificados por el Código civil mozambicano, donde se integra el DUAT. Este ejercicio se hará con una cierta racionalidad, teniendo en cuenta los derechos reales de goce y disfrute que, por su naturaleza y su contenido, están más cercanos del derecho en cuestión, pues entendemos que son aspectos esenciales, en comparación con el DUAT, el análisis de la posesión, la propiedad, el usufructo, el derecho de uso y ocupación o vivienda, enfiteusis y el derecho de superficie.

\subsection{Derecho de posesión y DUAT}

La posesión ${ }^{56}$ "consiste en el poder que se produce cuando alguien actúa de una manera correspondiente al ejercicio del derecho de propiedad u otro derecho real" ${ }^{57}$, que es susceptible de apropiación de manera personal o a través de otra persona.

La adquisición de la posesión, tanto en Mozambique como en España, supone la acumulación en una sola persona del corpus y del animus, es decir, el conjunto del dominio material de una cosa. La detención por la misma persona y la intención de tener el dominio del bien. La posesión puede también ser adquirida por la constitución posesoria y por la modificación del título de la posesión, según el artículo $1263 \mathrm{CCM}$.

Algo similar sucede en España ${ }^{58}$ con la posesión que aparece regulada en los artículos 430 a 466 Código Civil, donde consta como un hecho jurídico que se produce como consecuencia la emanación del derecho que una persona tiene sobre la cosa, a partir de la que se origina la tutela judicial (antes interdictos, y actualmente juicio verbal), la cual concede a su poseedor un gran número de presunciones a su favor y se fundamenta en la prohibición de la violencia y la consecución de la paz social. Así, la posesión se presume siempre de buena fe y se produce como consecuencia de dos elementos: el corpus (tenencia material de la cosa y posibilidad de ejercer una influencia inmediata sobre ella) y el animus (es la voluntad de poseer la cosa como dueño).

Sin embargo, España, a pesar de que la posesión consiste en la tenencia material sobre una cosa, la legislación reconoce como poseedor a personas que no poseen materialmente la cosa. Y en este sentido el "ius possesionis" consiste en la tenencia material y concreta sobre una cosa mientras que el "ius possidendi" es el derecho a poseer que ostenta una persona sobre una cosa pero que es poseída materialmente por otra. Es decir, la posesión de hecho es el poder que se ejerce sobre un bien (ius possesionis) y la posesión

52 PINTO, R. op. cit., p. 584 y s.

53 QUADROS, M., op. cit., p. 42 y 43.

54 GUNE, B. "Natureza juridica do direito de uso e aproveitamento da terra em Moçambique" (Dissertação de mestrado), FDUEM- Maputo, 2005, p. 159 y ss.

55 In CISTAC, G. y CHIZIANE, E., op. cit., vea CALENGO, A., p. 42 y ss.

56 En el buen sentido, claramente diferente de la simple detención, se trata la posesión en el artículo 1253 del CCM.

57 Cfr. El artículo $1252^{\circ}$ del CCM.

58 ALONSO PÉREZ, M.: "Meditaciones sobre la esencia y funciones de la posesión”. Diario La Ley, 1986, pág. 926, tomo 3, Editorial LA LEY. 
de derecho es la norma que reconoce la condición de poseedor aunque éste carezca de la detención material de la cosa (ius possidendi) ${ }^{59}$.

En Mozambique no es del todo así, pues la posesión se caracteriza por la situación de hecho y respecto a la posibilidad de ser titular o no titular, de buena fe o de mala fe, pacífica o violenta, pública o oculto, formalmente o no es diferente, pues cabe la constitución de un DUAT sobre una actuación indebida por parte de un funcionario del gobierno, por ejemplo. Como situación provisional la posesión tiene el efecto jurídico la presunción de la titularidad del derecho real, pero es una presunción iuris tantum. Sin embargo, se puede convertir en una situación definitiva si continúa por una duración determinada y si la posesión es pública y pacífica como resultado de la figura jurídica de la usucapion $^{60}$, que también es regulada en España bajo la usucapión por 30 años para inmuebles o de 6 para bienes muebles.

La duración de la posesión varía según el caso, tomando en cuenta los caracteres ellos mismos y de la naturaleza des bienes, de conformidad con el artículo 1295 del CCM. Y se asemeja a la regulada en el Código civil español donde con carácter general se habla para los bines inmuebles de plazos que van desde los 10 a los 30 años atendiendo a si están presentes o ausentes los propietarios mientras se ejecuta la posesión por quien no lo es, y aumentando al plazo máximo cuando además concurre la mala fe en el ejercicio de la posesión que pretende adquirir el bien a través de la posesión en concepto de dueño de manera continuada, publica y pacífica ${ }^{61}$.

La posesión en Mozambique tiene formas específicas para su protección, atendiendo a la situación concreta, específicamente en el caso de una amenaza, perturbación del ejercicio de este derecho, o incluso bajo la usurpación. En este marco, una posesión que sea efectiva, de buena fe y pública se puede defender a través de los medios judiciales y extrajudiciales, incluyendo acciones preventivas, la acción posesoria y acción para la restitución de la posesión, así como acción directa y la legitima defensa ${ }^{62}$.

La extinción de la posesión puede ser realizado por no uso, abandono, pérdida o destrucción física de la cosa, o de la expropiación, la cesión o la posesión por un tercero contra la voluntad del poseedor anterior, en este caso el nuevo poseedor tiene una posesión de más de un año.

La naturaleza jurídica de la posesión es cuestionable, según OLIVEIRA ASCENSAO es un derecho relativo y MENEZES CORDEIRO considera que estamos frente a un derecho real de gozo atípico o anormal, lo que es diferente en España, porque aquí el derecho posesión se define como un derecho real donde el poseedor tiene menos facultades que el propietario, pero no se le clasifica como derecho real atípico. Estamos de acuerdo con RUI PINTO, quien juzga que la posesión no es un derecho real, sino una situación de hecho ${ }^{63}$, que se vuelve jurídica cuando se producen los requisitos legalmente recogidos y

59 LECIÑENA IBARRA, ASCENSIÓN: “Concepto legal de usufructo". Esta doctrina forma parte del libro" Tratado de usufructo “, edición n. ${ }^{\circ} 1$, Editorial LA LEY.

60 Según los artículos 1268, nº 1,1293 hasta 1300, del CCM.

61 COVO OLVERA, T.: "Esta doctrina forma parte del libro "Régimen jurídico de los bienes de las entidades locales", edición n. ${ }^{\circ}$ 1, Editorial LA LEY, Madrid, 2006.

62 Vid. los artículos 1276 hasta 1279 y 336-337, todos del CCM. Para tener más detalles invitamo los a consultar: CALENGO, A., op. cit., p.42-43 y MOREIRA, A. p. 126 - 127.

63 PINTO, R. op. cit., p.590. 
bajo los que el poseedor es amparado. Y es que esta es una diferencia con respecto a España donde la posesión tiene, tal y como hemos expuesto, dos ámbitos de ejercicio tanto bajo la posesión de hecho como bajo la posesión de derecho.

Estos dos derechos (derecho de posesión y derecho de uso y disfrute de la tierra) son realidades jurídicas que no deben ser confundidas ${ }^{64}$, pues la posesión existe en relación con cualquier bien, contrariamente a lo que sucede con el DUAT que solo reposa sobre la tierra.

El DUAT es un poder para uso y usufructo de una parcela de tierra propiedad del Estado, que no significa el dominio material de la tierra, por el titular del DUAT. Este derecho se puede adquirir por ocupación o por una solicitud de autorización administrativa. El DUAT se caracteriza por la posibilidad de ser titularizada o no, de buena fe, pacífica, pública y causal, dando a su titular el dominio real, útil y exclusivo de la parcela. Esto asegura el uso y usufructo de la cosa. Sin embargo, esta realidad no conduce a la apropiación de las tierras en cuestión a través de la usucapión ${ }^{65}$.

La posesión puede representar la protección de un sujeto que se encuentra en una situación potencial para convertirse en titular de ese derecho. En relación con el derecho a la propiedad, la posesión funciona como medio de protección de la atribución de la cosa a una persona determinada, esperando un posible reconocimiento del derecho de propiedad. Sin embargo, la función de DUAT es de naturaleza totalmente contraria. De hecho, el DUAT permite al titular el gozo del derecho definitivo, completo ${ }^{66} \mathrm{y}$ original.

Podemos remarcar que la posesión tiene el propósito potencial en la posición jurídica del poseedor de hacerlo adquirir el derecho de propiedad, mientras que el DUAT no puede considerarse como una posesión, porque no es su propósito legal la constitución del derecho de propiedad sobre la tierra, a favor de los titulares de la DUAT.

En el caso de una situación de amenaza o perturbación del ejercicio del DUAT, su titular podrá utilizar los medios de protección judicial y extrajudiciales aplicables a los derechos reales, con carácter general, pero no como propietario porque no lo es.

Las modalidades de la extinción del DUAT son más amplias y diferentes a los de la posesión. La extinción del DUAT puede resultar de la falta de cumplimiento del plan de exploración, por la expropiación de utilidad pública, al final del plazo o de la renuncia del derecho, según el artículo 18 de la LT-1997.

La estructura jurídica de la posesión, ciertamente es muy cercana a la del DUAT, pero no debe confundirse a ella, pues el DUAT tiene una estructura propia como se ha demostrado. La posesión aparece en la Ley Tierras de1997, a través de la figura legal de la ocupación, según el artículo 12, y ella es simplemente una manifestación de la ocupación.

En resumen, los dos derechos - de posesión y el DUAT - indudablemente se superponen en lo que a algunas facultades en el ejercicio de sus derechos corresponde; pero sin olvidar que mientras la posesión se basa sobre la tierra, el DUAT incluye la posesión de la parcela de la misma, pero sin limitarse a la posesión. Por ello, la posesión puede tener

64 Nosotros compartimos la posición de los autores: CALENGO, J. op. cit., p. 43 y GUNE, B. op. cit., p. 152 y ss.

65 Este razonamiento resulta del articulo 109 de la CRM-2004, que limita la apropiación privada de la tierra.

66 Respetando las limitaciones, que ya hemos subrayado. 
una incidencia en diferentes bienes materiales o corporales o no; a diferencia del DUAT, que sólo se centra sobre la tierra.

\subsection{Derecho de propiedad y DUAT}

La doctrina y el Derecho comparado no ofrecen ningún concepto de derecho de la propiedad, excepto desde una perspectiva descriptiva, al igual que sucede en España. Por lo tanto, el Derecho positivo Nacional establece que este derecho es un "Disfrute pleno y exclusivo de derechos de uso, usufructo y disposición de las cosas por su maestro o titular, en plena conformidad con los límites establecidos por la ley y respecto de las prohibiciones bajo la ley"67.

El derecho de la propiedad está reglamentado por el artículo 1305 y siguientes del CCM y se considera como un derecho real principal, ya que asegura el disfrute de todas las situaciones indicadas en el párrafo anterior.

En relación con las tres prerrogativas de la propiedad, nosotros subrayamos el poder de disposición, que se manifiesta de dos maneras: el poder de disposición legal (donar, gozar de los derechos reales de disfrute, disponer, renunciar, etc.) y el poder de disposición material (la transformación de la cosa, a través de las mejoras útil, necesario y suntuosas).

El derecho de la propiedad puede ser adquirida a través de la transferencia inter vivos o mortis causa, por ocupación, usucapión y según otras modalidades previstas en la Ley. Este derecho se caracteriza esencialmente por el poder directo, inmediato y exclusivo sobre la cosa, sin la necesidad de la cooperación de una tercera persona. Es un poder indeterminado desde el punto de vista de su contenido, ya que varía de caso por caso y según la naturaleza de la cosa. Los derechos reales limitados tienen un contenido preciso y claramente establecido por ley y por las partes, mientras que, en el derecho de la propiedad es diferente.

El derecho de la propiedad en Mozambique es indeterminado, pero su extinción puede manifestarse como la transmisión, abandono o deterioro de la cosa.

La amenaza o perturbación del ejercicio de eso derecho en el caso de perturbación o usurpación, el titular del derecho puede protegerse a través de acciones del derecho privado, como las acciones reales, la acción directa y la legítima defensa, usando medios judiciales y extrajudiciales.

Según BOAVENDTURA GUNE, el DUAT no se integra en la figura legal del derecho de propiedad por varias razones:

En primer lugar, porque el derecho de propiedad se basa en todos los bienes materiales o corporales e inmateriales o incorporales, mientras que él DUAT solo se basa en la tierra.

Después, parece que el derecho de la propiedad confiere al titular el dominio directo sobre la cosa, traducida en el poder de uso, usufructo y disposición, por el contrario,

67 Vid. articulo 1302 de la CCM. 
el DUAT confiere al titular el dominio útil ${ }^{68}$ traducido esencialmente en el uso y disfrute de la tierra.

En tercer lugar, según CALENGO, todo se explica "por la contradicción de tener dos derechos de propiedad sobre la misma cosa, a pesar de su diferencia en la calidad, es decir, entre las propiedades del Estado y una eventual propiedad de quienes la usan. Lo que en España sería el derecho de tenencia inmediata bajo posesión diferenciada del derecho de propiedad que corresponde salvo error al titular inscrito en el Registro de la Propiedad.

Pero en Mozambique, la doctrina diferencia para el caso de paridad (igualdad cualitativa) entre las facultades del titular de DUAT y facultades del titular de la propiedad del Estado, la solución sería el reconocimiento de una la copropiedad que casi es lo que existe" ${ }^{69}$. Todavía, la posición del Estado ante el titular de la DUAT es por mucho muy diferente, el Estado tiene, por ejemplo, funciones administrativas y de control sobre la tierra. Sin embargo, esta "copropiedad" no sería así entendida en España, pues cuando la Ley 19/95 de Modernización de las Explotaciones Agrarias define la explotación agraria como "el conjunto de bienes y derechos organizados empresarialmente por su titular en el ejercicio de su actividad agraria, primordialmente con fines de mercado, y que constituye en sí misma una unidad técnica económica, admitiendo explotaciones con diferentes características, donde la persona responsable de la utilización de la tierra es el empresario porque es el que tiene la tierra en explotación con sus requisitos de organización, responsabilidad, profesionalidad y economicidad. Este carácter de empresario se puede tener además gozando de la nuda propiedad de la tierra porque constituye la titularidad directa o bien cuando no es propietario y entonces su titularidad es indirecta, este caso es muy frecuente en la agricultura con distintas formas, aunque destacan dos principalmente: el arrendamiento y la aparcería.

En cuarto lugar, el derecho de la propiedad significa que su titular tiene, en principio, poderes plenos y absolutos ${ }^{70}$ de autoridad sobre la cosa. El propietario es el dueño de la cosa. En el DUAT, los poderes sobre la cosa - la tierra - son muy limitados, por una variedad de razones, incluyendo las necesidades de asegurar la distribución de la tierra, dependiendo de la orientación de la PNT, promoción del desarrollo económico y social y las posibles necesidades de la reforma que afecta a la Política de tierras.

En quinto lugar, el derecho de la propiedad sobre la tierra no asegura el gozo directo por el Estado, esto es, el uso y disfrute de la tierra. A través de su derecho el Estado permite solamente la administración más racional y organizada de la tierra, un bien tan esencial para las empresas y la sociedad mozambiqueña en permanente transformación.

En sexto lugar, el derecho a la propiedad es un importante derecho real, a diferencia de DUAT, que puede ser considerado un derecho real menor o limitado, en la medida en que la propiedad de la tierra pertenece al Estado.

68 Vea, para más detailles PEREIRA, C e BALTAZAR, R. " Reflexões sobre o regime jurídico da terra ». Editor Elvetas, 2005, p.9.

69 Vid. CALENGO, A. op. cit. , p. 45.

70 En este caso podemos decir que los "poderes plenos y absolutos" son problemáticos porque el mismo el Estado, dueño de la tierra, no puede disponer libremente de ella, ya que por ejemplo, no puede vender. 
En resumen, podemos sin duda afirmar que el DUAT es un derecho real menor y representa una de las limitaciones de la propiedad del Estado sobre la tierra, porque el DUAT es una situación onerosa a los derechos del Estado sobre la tierra.

\subsection{Derecho de usufructo y DUAT}

El usufructo otorga el usufructuario "el derecho al uso temporal y pleno de una cosa o goce del derecho de un tercero, sin hacer la modificación de la cosa cuanto a la forma y a su sustancia”, según el artículo 1539 del $\mathrm{CCM}^{71}$. De tal manera que el usufructo tiene la función de conferir a su titular un derecho de goce limitado y temporal. Lo que es análogo en España, cuyo Código civil en el artículo 467 lo define como el "derecho a disfrutar los bienes ajenos con la obligación de conservar su forma y sustancia, a no ser que el título de su constitución o la ley autoricen otra cosa", es decir, cuando una persona posee el usufructo de un bien tiene derecho a su uso y disfrute, pero no tiene su propiedad. Es por ello que se caracteriza ser un derecho real en cosa ajena, cuyo objeto del usufructo no forma parte del patrimonio del usufructuario si no del patrimonio del nudo propietario; si bien, es un derecho de disfrute completo bajo el que el usufructuario podrá disfrutar de todos los aprovechamientos de la cosa usufructuada, por un tiempo ya que es un derecho temporal que nunca puede constituirse como indefinido.

Por lo tanto, es un derecho real que limita el dominio directo sobre una cosa o derecho de un tercero. El usufructo se presenta como una desmembración de la propiedad, ya que combina dos atributos despojados del derecho a la propiedad.

El efecto del usufructo es el uso, el disfrute y la administración de la cosa o derecho, según el destino económico respectivo. Los cambios de duración basan en la calidad de la materia, es decir, según si una persona privada o una persona jurídica. En el primer caso, referido al usufructo no puede exceder la vida del usufructuario, mientras que en el segundo caso, no podrá exceder de 30 años.

Para la protección de este derecho, los medios jurisdiccionales y no jurisdiccionales, aceptado por los otros derechos de propiedad, son válidos.

La extinción del usufructo los resultados según el artículo 1476 de la muerte del usufructuario, al final del período, la unificación del usufructo y propiedad, de la pérdida total del buen objeto del usufructo, o renuncia.

Sin entrar en detalles, la confrontación entre el derecho de usufructo y el DUAT nos lleva a las siguientes conclusiones:

- El usufructo da su titular uso, el disfrute y la administración de la propiedad o el derecho por un período determinado generalmente y por lo tanto es limitada mientras que el DUAT en lugar de ello puede dar el uso y el disfrute por un período indefinido, en el caso de habitual y ocupación en el caso de la vivienda, según el artículo 12 y 17, n 2 de la ley de la tierra en 1997.

71 CORNU, op. cit. p. 889, el usufructo se define como "el derecho real temporal esencialmente, en la mayoría de los casos su titular tiene la otorga del uso y disfrute de todo tipo de bienes pertenecientes a un tercero, pero con la responsabilidad de retener la sustancia". 
- Mientras que el DUAT se destinada a permitir la transformación de la tierra, esencialmente a través del trabajo humano.

- El usufructo implica una relación jurídica entre el propietario o titular del derecho con el usufructuario.

Por el contrario, el DUAT consiste: por un lado, una relación entre el titular de ese derecho y el Estado; y por el otro, de una relación entre el titular de la DUAT y terceras personas posiblemente interesadas en la misma tierra.

En suma, el DUAT coincide con el derecho de usufructo, en lo que concierne al uso y disfrute de la propiedad. Sin embargo, es diferente, porque el usufructo puede basarse en cualquier bien mueble o inmueble y, en consecuencia, es mas amplio que el DUAT, derecho que solo puede desarrollarse sobre el bien inmueble de la tierra.

En España, se permitiría que el usufructo sobre la finca o explotación pueda ser hipotecada con acceso al crédito, porque la nuda propiedad puede ser hipotecada independientemente, puesto que el propietario mantiene el poder de las facultades restantes no cedidas al usufructuario, que presentan sin lugar a dudas un contenido y valor económico que le otorgan suficiente significación material como para constituir su objeto, como se demuestra por Moreno Quesada en relación a la posibilidad del usufructo de la nuda propiedad, del que nos ocuparemos más adelante ${ }^{72}$.

A juicio del autor, el carácter real «erga omnes» que presenta el derecho de usufructo permite el que se atribuya el goce de la nuda propiedad a persona distinta de su primitivo titular, en cuanto que este hecho no podrá influir en el aprovechamiento que corresponde al usufructuario, por lo que no son obstáculo para la constitución del usufructo de la nuda propiedad los arts. 489, 595 y concordantes del Código Civil (13) .

\subsection{Derecho de uso y disfrute y DUAT}

El derecho de uso "consiste en la capacidad para usar el bien y obtener sus frutos, atendiendo a las necesidades o del titular, o de su familia", pues solo se usa en el ámbito urbano para las viviendas bajo el derecho de habitación. Y como derecho real puede ser adquirido por contrato, a través de testamento o disposiciones legales. Estos derechos de detención y el uso de la propiedad, la medida de las necesidades de su dueño y su familia.

Estos derechos son de longitud variable basado en el acuerdo entre las partes y si se oponen a una violación, lesiones, daño, amenaza, su protección jurídica se logra a través de los medios extrajudiciales y válida para todos los derechos reales.

El choque entre los derechos de uso y habitación con el DUAT, da como resultado que derecho puede basarse en todos los bienes tangibles, así el derecho a la vivienda se basa solamente en el edificio de apartamentos, mientras que el DUAT descansa en la tierra.

Otra diferencia es que los derechos de uso y ocupación se traducen en el uso de la energía y disfrute de la propiedad en la medida de las necesidades de su titular o de su

72 ALBALADEJO GARCÍA, M: "El usufructo de la nuda propiedad”. A.D.C., abril-junio, 1959, págs. 549 a 551. GUTIÉRREZ JEREZ, L.J.: "La hipotecabilidad del derecho de usufructo". Actualidad Civil, N. o 20, Quincena del 16 al 30 Nov. 2009, pág. 2365, tomo 2, LA LEY. 
familia, en lugar de DUAT, cuyo reconocimiento no se limita a las necesidades del propietario y su familia.

Además, encontramos mas diferencias: los derechos de uso y habitación son transferibles, pues no permiten que el sostenedor venderlos, alquilarlos o honor de ninguna manera. Sin embargo, el DUAT que es transferible entre vivos y la causa de muerte mortis según el artículo 16 de la ley de la tierra en 1997.

Así se puede considerar que estos tres derechos reales tienen un marco y contenido variado, pero si el derecho a utilizar tiene un impacto en la tierra, se ajusta a los DUAT.

\subsection{EI DUAT y enfiteusis}

La enfiteusis es un derecho derogado en Mozambique si bien no lo es en España, aunque su uso no es frecuente, pero para determinar la naturaleza de los DUAT consideramos útil su análisis. De hecho, es en el desmembramiento de la propiedad en los dominios directos y útiles lo que nos parece interesante para este análisis pues como establece el Código civil de Mozambique la zona pertenece a los propietarios mientras que el dominio útil pertenece al arrendatario o al colon.

La enfiteusis en Mozambique tenía la función de atraer al productor de la tierra, de la que se obtenía una renta baja, pues los terrenos eras poco fértiles y productivos. Su naturaleza jurídica es equivalente en España, cuyo Código civil en el artículo 1604 regula la constitución del censo a cuando "se sujetan algunos bienes inmuebles al pago de un canon o rédito anual en retribución de un capital que se recibe en dinero, o del dominio pleno o menos pleno que se transmite de los mismos bienes". Añadiendo a continuación la clasificación de tres tipos de censo: enfitéutico (es el que aun se aplica aunque sea de manera residual), consignativo y reservativo ${ }^{73}$.

Artículo 1605: Es enfitéutico el censo cuando una persona cede a otra el dominio útil de una finca, reservándose el directo y el derecho a percibir del enfiteuta una pensión anual en reconocimiento de este mismo dominio.

- Artículo 1606: Es consignativo el censo, cuando el censatario impone sobre un inmueble de su propiedad el gravamen del canon o pensión que se obliga a pagar al censualista por el capital que de éste recibe en dinero.

- Artículo 1607: Es reservativo el censo, cuando una persona cede a otra el pleno dominio de un inmueble, reservándose el derecho a percibir sobre el mismo inmueble una pensión anual que deba pagar el censatario.

Así en España al igual que sucedía en Mozambique cuando estaba vigente esta figura, "la naturaleza del censo que la cesión del capital o de la cosa inmueble sea perpetua o por tiempo indefinido; sin embargo, el censatario podrá redimir el censo a su voluntad aunque se pacte lo contrario; siendo esta disposición aplicable a los censos que hoy existen", pues aunque puede pactarse "que la redención del censo no tenga lugar durante la

73 GONZÁLEZ MARTÍNEZ, A.: "La enfiteusis: aspectos básicos de esta institución”. @ Revista de la Facultad de Ciencias Sociales y Jurídicas de Elche Volúmen I - Número 4 - Enero de 2009 - págs. 251-267 - ISSN: 1886-6611 https://revistasocialesyjuridicas.files.wordpress.com/2010/09/04-tl-03.pdf 
vida del censualista o de una persona determinada, o que no pueda redimirse en cierto número de años, que no excederá de veinte en el consignativo, ni de sesenta en el reservativo y enfitéutico" (art. 1608 Cc español).

Así, la enfiteusis, según quedaba regulada en Mozambique, era por contrato, testamento o usurpación, y consistía en la propiedad de bienes por parte del arrendatario de larga duración, con la capacidad de utilizar y dar buen uso durante un período indefinido el inmueble.

Las diferencias entre la enfiteusis y los DUAT existen, pero parten de un un aspecto en común, como es el impacto sobre el área útil de la propiedad o función social y el hecho de uso directo sobre la tierra. En ambos casos, la titularidad de la tierra pertenece a una persona distinta de quien la usa y disfruta, pues en la enfiteusis el enfiteuta será el propietario y en los DUAT ese propietario es el Estado.

En definitiva, el DUAT es distinto que el contrato de arrendamiento a largo plazo en todos los puntos de vista no puede reducirse a la enfiteusis, viceversa, a pesar de que ambos derechos manifiestan el área útil del objeto de la ley.

\subsection{Derecho de superficie y DUAT}

El derecho de superficie en Mozambique queda regulado como "la capacidad para construir o mantener, de manera perpetua o temporal un edificio en el terreno de los demás, o para hacer o mantener una plantación en la tierra de otros". Y puede ser adquirido por contrato, testamento o usurpación, además de poder constituirse como resultado de la enajenación de una construcción o árboles existentes, en la separación con la propiedad de la tierra, que es donde se incluye el uso y el disfrute del área útil para los efectos de la construcción y/o plantación de árboles. Esto representa el efecto jurídico de los derechos de superficie, porque el dueño de la tierra retiene el derecho a explotar el subsuelo.

En cuanto a la duración, esta es generalmente indeterminada, pero puede ser limitada por un plazo específico. Y durante su vigencia, si el derecho de superficie es objeto de una perturbación en su ejercicio, el propietario puede defenderse vía judicial o extrajudicial como cualquiera otro derecho real.

Finalmente, su extinción se regula en el artículo 1536 del CCM, como la falta de la conclusión del edificio o plantación en el plazo concedido, la ausencia de reconstrucción o renovación de los plazos de la plantación, el cumplimiento del tiempo, unificación por la misma persona de la zona derecha y el derecho a la propiedad, la desaparición o la inutilización de la tierra y la expropiación por razón de utilidad pública si no cumple con la función social que le es propia.

A partir de esto, la pregunta que nos surge es su los DUAT podrían integrase en el derecho de superficie. Pues cuando comparamos ambas instituciones podemos concluir que estos dos derechos tienen su impacto respecto del uso en la parcela de tierra, ambos permiten la construcción de edificios y la siembra y mantenimiento de árboles atendiendo al fin económico de la parcela, y a su función social.

Sin embargo, el derecho de superficie se constituye por un período indefinido, mientras que el DUAT solo puede ser indefinida en el caso de vivienda, comunidad uso y operario de la familia, porque para los operadores agrícolas su duración es determinada; 
y durante su vigencia permite mayores derechos a quien es titular de un derecho de uso y disfrute respecto de llevar a cabo construcciones o plantaciones que en lo que afecta al contenido del derecho de superficie.

\section{NATURALEZA JURÍDICA DEL DUAT}

Después de analizar bajo el Código civil de Mozambique los diferentes derechos reales que tienen similitudes con el DUAT, concluimos que la naturaleza jurídica del DUAT.

Para apreciar la naturaleza jurídica de DUAT, es decir, su contenido, su clasificación dentro de los derechos reales y los principios que guían este derecho, si se deriva del derecho público o derecho privado, llamamos la atención a las tesis más representativas, que incluyen la tesis de la proximidad con el derecho de propiedad (B), la teoría del verdadero derecho suis generis o anormal (C), de un verdadero derecho real (A) y la tesis de un derecho real de carácter híbrido (D).

\subsection{La tesis del DUAT como verdadero derecho real}

Apoyado por BOAVENTURA GUNE, esta tesis se basa en la idea de que la confrontación de DUAT los derechos reales de disfrute elegido permite para considerar que la DUAT probablemente es un derecho real porque se basa en una cosa, la tierra, según el artículo $1, \mathrm{n}^{\circ} 2$ de la ley de Tierra de 1997.

Por lo tanto, el titular tiene una activa posición contra la posición pasiva de todos los demás. Y los terceros puede no disturbar el ejercicio del derecho. La posición actual del dueño de la DUAT implica los poderes y prerrogativas bajo la ley en el campo y frente a terceros. La naturaleza real de la DUAT también resultados del evento, en ese derecho, características comunes a todos los derechos reales, por ejemplo, la tipicidad o la prevalencia.

GUNE añade el DUAT es un derecho real, el contenido de que vacíe los otros derechos reales y neutraliza legalmente. Según el autor, sería posible revocación de otros derechos reales, una vez que sus prerrogativas y poderes, con excepción de las facultades de disposición del derecho de propiedad, encaja en la DUAT.

Esta tesis se basa en argumentos lógicos, pero no lo suficiente, porque ella tiene en cuenta las especificidades de DUAT, incluyendo condiciones de compra y el grado de la energía de goce concedido al titular.

\subsection{La tesis de la proximidad con el derecho de propiedad}

María QUADROS puede considerarse pionero en esta tesis. Ella defiende que los poderes otorgados a los titulares de la DUAT son tan amplios que pueden confundirse con el derecho de propiedad. De hecho, el actor dice que el alcance de las competencias atribuidas a los titulares de la DUAT puede conducir como el verdadero dueño de la tierra en Mozambique.

QUADROS va a decir que los arquitectos de la ley de la tierra en 1997 intentaron despedir a DUAT de posesión y él tan cerca como sea posible del derecho a la propiedad que se asignaría a los usuarios de la tierra. 
Puntos de proximidad a DUAT al derecho de propiedad se basaría, a las distintas modalidades de adquisiciones de esta ley permitida por la ley, la posibilidad de Constitución de servidumbre, a los medios de protección legal contra la violación de la DUAT, a la posibilidad de participar en cotitulares a la posibilidad de transmisión.

¿La tesis de la proximidad de la DUAT al derecho de propiedad es válida?

No estamos de acuerdo con esta tesis porque ya hemos demostrado que el derecho a la propiedad es un derecho real principal, mientras que el DUAT es derecho real menor o limitado en la medida en que la propiedad de la tierra vuelve al estado. Artículo 109, n ○ 1 de 2004 CRM es claro: "La tierra es propiedad del estado".

Esta tesis no mide las consecuencias jurídicas de sus propuestas, porque en el nivel de propiedad de la tierra, por ejemplo, daría lugar a confusión, debido a la existencia de dos propiedades, situación contraria al principio constitucional declarado por artículo 109, $\mathrm{n}^{\circ} 1$, el CRM de 2004.

\subsection{La tesis del derecho real sui generis}

Esta tesis es apoyada fuertemente por CALENGO André. Pone énfasis en el hecho de que el DUAT es un derecho real que se ajuste a los derechos reales de goce, porque garantiza a los titulares del uso y usufructo de la tierra.

Según CALENGO dado el régimen jurídico de los derechos reales típicos de DUAT en el código civil de Mozambique (CCM) no es posible incluir este derecho en los derechos reales del CCM. En este contexto, las afirmaciones del autor que sin duda estamos en presencia de un verdadero derecho, sin embargo, no está tampoco el derecho a la propiedad. Así, dependiendo de la estructura y el contenido de la DUAT, el autor considera DUAT como un derecho real sui generis o atípicos.

El carácter anormal se justifica por las normas jurídicas y la disciplina legal de las soluciones originales de DUAT, incluyendo:

- la negativa de la mayoría de los poderes de disposiciones;

- la protección especial de los derechos de las mujeres;

- reconocimiento de las normas y prácticas consuetudinarias, con algún tipo de paridad con las normas de derecho positivo, en la regulación de los hechos de la Constitución, transmisión, extinción del uso y el uso de la tierra;

- la introducción de la comunidad local como sujeto de derecho y esta entidad no tiene la necesidad de reconocimiento de su personalidad jurídica para el ejercicio de su derecho;

- $\quad$ el uso de la figura jurídica de la ocupación en un sentido sui generis; y

- una violación de ciertas reglas del derecho civil, especialmente relacionadas con registros y evidencia.

Esta tesis nos parece más respetuoso de los principios constitucionales y el régimen legal de DUAT establecida por la ley de la tierra en 1997, porque es incuestionable en cuanto a la integración de DUAT en derechos reales. El autor destaca las características 
del plan y luego este nuevo \&gt; de esta nueva ley. Esto parece muy importante porque, por un lado, la tesis propone la aplicación del régimen de la ley de la propiedad, y por otra parte, esta tesis proporciona el general régimen de derecho de propiedad para ser aplicado con necesario cambia cuando la ley de tierras 1997 no tiene sus propias soluciones

\subsection{La tesis de un derecho real de naturaleza hibrida o mixta}

Hemos defendido la primera vez esta tesis en el "Simposio sobre diez años de la ley de la tierra en Mozambique en 2007”. Es más por lo menos el desarrollo de la tesis anterior, con alteraciones significativas.

Ponemos énfasis en el contenido de la DUAT y el otro en el sistema de solución de controversias y los principios que guían la DUAT. Esta perspectiva es el resultado del debate público y aspectos que aclarar.

De hecho, el contenido y la estructura de la DUAT deben obtenerse de la orden legal de Mozambique. Probablemente coincidimos con GUNE y CALENGO que consideran que el DUAT encaja dentro de los derechos reales, por supuesto, sui generis, así demostrado por CALENGO.

El DUAT es un derecho real de carácter híbrido, es decir, debe sufrir según la situación concreta de los principios o normas de derecho público y derecho privado. De hecho, la diversidad de contenido DUAT da una heterogeneidad evidente. Específicamente llamó a ambas técnicas de derecho público y derecho privado.

Se traduce también por la aplicación de normas específicas sobre raíces (v. aplicación del artículo 16, No 1, de la ley de la tierra en 1997) mentira así en una perspectiva de derecho civil, por el desarrollo de competencias público, colocando en perspectiva de derecho público fundamentalmente desiguales, dado por ejemplo a las autoridades de las comunidades locales, gestión de la tierra y resolución de conflictos.

También debemos añadir que el estado tiene la responsabilidad principal para la administración de la tierra, incluyendo en el reparto de tierras, según el artículo 12 de la ley del suelo de 1997 (LT) de 1997.

Reflexión sobre la naturaleza jurídica de DUAT debe permitirnos trazar una línea clara entre los procesos de derecho público y derecho privado. Como Christian DUPEYRON “... existen raramente puro.” Nos estamos enfrentando como dice Dunn a la necesidad de «conciliar las exigencias del interés general y la protección de las personas a veces condujo a la legislatura a subordinar la acción administrativa a la voluntad de las personas privado... »

Puede demostrarse el carácter híbrido de la DUAT en cuanto a la elección de los medios de protección legal de DUAT, en caso de violación de este derecho.

Si el conflicto es el resultado de una relación jurídica administrativa, es decir, entre el estado a un individuo, como parte de la administración pública, por ejemplo, la asignación por parte del estado una parcela de tierra, a la culpa o negligencia, a dos individuos diferentes. En una relación de carácter público, con dos actos administrativos, el conflicto es responsabilidad del Tribunal Administrativo (sección 230, $\mathrm{n}^{\circ}$, cláusula b del CRM 2004), mediante la aplicación de los principios y normas de derecho público. 
Si el conflicto, por el contrario, ajusta dentro de las relaciones jurídicas privadas, es decir, entre individuos, por ejemplo, un conflicto resultante de la gestión o la extinción de la copropiedad de DUAT, entre miembros de una comunidad local, la Tribunales civiles se agarran, mediante la aplicación de principios o normas de derecho privado.

Propiedad incluye las siguientes competencias: (derecho a usar su pozo) usus, fructus (derecho a gozar de los frutos de su propiedad), reducido a una tierra simbólica alquiler pagado y el abuso (derecho a disponer de su propiedad para vender o la) en adelante), limitada por las disposiciones que restringen la venta.

\section{EL FUTURO DEL DUAT}

Aquí, queremos hacer dos observaciones muy brevemente, incluyendo la justificación para la creación del DUAT A), conduce a la discusión de la importancia de continuidad y mantenimiento o no del DUAT B).

\subsection{La justificación para la creación del DUAT}

El estudio del origen de DUAT, realizado en el capítulo II, llegó a la conclusión de que desde el punto de vista histórico, la DUAT nació como resultado de la independencia de Mozambique, a través de la consagración en la CRM-1975, del principio de propiedad de la tierra por el estado, sino también la tierra era considerada como un medio de creación de riqueza y por lo tanto un derecho de todo el pueblo de Mozambique \&gt; ¿por qué en cursiva?

GUNE Boaventura dice que "el origen y la justificación de la DUAT tiene una relación directa con el material de fuente, moral, política e ideológica de la población de Mozambique, adquirida durante la lucha por la liberación del país. Mozambique señala a la ideología y el sistema económico de los países que han apoyado esta lucha. Así, el país ha incorporado y aplicado la experiencia soviética de la colectivización de la tierra, desde la perspectiva de la construcción de una sociedad de economía planificada, vista al tiempo como la única forma compatible con los intereses nacionales."

Así, con la nacionalización de la tierra, el estado creó una situación jurídica en la que la propiedad de la tierra es adscripto uso y fruición, en la medida en que el estado se quedó con la zona, y concedió a los ciudadanos y otros Morales, el campo útil a través de la figura de DUAT.

El DUAT en primer lugar se presenta inicialmente como una subjetiva, cuanto derecho incluye poderes y facultades que el estado, subsidios a través de la ley de la tierra a los ciudadanos y otras personas jurídicas. Pero, por otro lado, es un derecho subjetivo de naturaleza pública desde el punto de vista de sus orígenes, porque la DUAT tiene dignidad constitucional y es un derecho de eficacia absoluta.

\subsection{Necesidades para mantener o reformar el DUAT}

Esta cuestión es actual y capital para la gestión de la buena tierra en Mozambique. Parece que la elección debe estar basada tanto en la situación real del país y de la económica y social "eficacia" que puede traer la opción de hacerlo. 
En este sentido, el debate entre la tesis esencialmente dos. La continuidad de DUAT en una mano y de la revocación, o incluso la privatización de la tierra por otra parte.

La tesis de la continuidad, manteniendo la DUAT en Mozambique se basa en los siguientes argumentos.

En primer lugar, justifica que la falta significativa de la aplicación de la filosofía de DUAT, desde 1975 hasta los años de 1992, en gran medida debe estar asociada con la guerra civil. Obviamente la situación política y militar ha obligado a Mozambique a reconsiderar su situación interna en el contexto de la especulación internacional y a redefinir su forma.

Entonces, ella pone de relieve la ineficacia de la condición de la tierra en algunos países como Zimbabwe, Namibia, y Sudáfrica es cuestionable por lo menos. Estos países, eligieron la privatización de la tierra después de su independencia, y están teniendo actualmente muchos problemas relacionados con la gestión de tierras, con los límites de acceso a la tierra, y conflictos relacionados con la distribución de la tierra.... Así, esta tesis sostiene que Mozambique debe mantener el dominio público y, desconfíar de la eficacia de la privatización, seguida por los países de la SADC y encontrar su propio camino.

En tercer lugar, la condición jurídica de la tierra, marcada por el sistema de la propiedad de la tierra por el estado y DUAT, puede garantizar la seguridad de una tierra para los agricultores y familias rurales. Al mismo tiempo, política de tierras y ley de la tierra han establecido medidas para la promoción de la inversión privada. Por ejemplo, acceso a la tierra es proporcionado por los LT de 1997, artículo 10 y siguientes, y DUAT para inversores dura 50 años, renovables.

En cuarto lugar, la tesis de la continuidad sugiere que cambie la situación jurídica de la tierra para llevar a cabo una evaluación de la necesidad social de este nuevo proyecto y el impacto de las medidas propuestas. La metodología legislativa, según Jean-Louis BERGEL "incluye los procesos de evaluación disposiciones predictivo y retrospectivo.

En quinto lugar, la "juventud" de la ley de la tierra, aprobada en 1997, tras un debate muy participativo y consensual nacional y la evaluación de lo social necesita para una posible reforma del estatuto de la tierra firme durante la "Simposio sobre 10 años de la ley de tierras, en 2007", justifica la continuidad de la DUAT y propiedad de la tierra por el estado.

De hecho, la síntesis del simposio celebrado en la una mano que "la ley del suelo ha sido diseñada como una herramienta para el desarrollo, garantizar el primer derecho a la tierra de la gente y la promoción de alianzas entre comunidades locales y el sector privado e t promoción de la inversión en las zonas rurales, en particular en el sector agrícola". Por otro lado, resulta que la ley en la tierra «reconoce al mismo tiempo, la tierra como una propiedad del estado y la existencia de los derechos territoriales de los individuos, muy fuertes, con medidas de protección jurídicas frente a terceros y al estado»

Así, esta tesis demuestra que hay una especie de consenso en el país, según la cual la tierra debe seguir siendo propiedad del estado y que los individuos deben disfrutar el DUAT. Sin embargo, se debe aclarar el contenido y garantías de los derechos sobre la tierra asignan a los individuos, incluyendo las comunidades locales y también establecer 
mecanismos legales para la movilidad o la transmisión de DUAT, especialmente en presencia de la inversión en la tierra.

Por el contrario, estamos claramente contra la continuidad, manteniendo la DUAT en Mozambique teniendo en cuenta nuestra realidad social, económico y político. Para la revocación de la DUAT y son favorables a la privatización de la tierra.

En definitiva, compartimos apreciaciones de Philipe DELVILLE sobre el debate "privatizar u obtener de la tierra". Considera acertadamente que "construir un régimen jurídico de la propiedad privada de la tierra toma una fuerte inversión del estado, catastros bien organizados, registro de cambios...". Añade que "la transformación de la tierra en un buen comerciante primero es el resultado de procesos históricos y no se decreta desde arriba. Una política de privatización es probable tener éxito sólo en contextos específicos, donde la individualización de los derechos ya ha alcanzado un alto nivel". Este es el caso de Mozambique.

Mozambique, con menos de 40 años de la independencia, marcada por la economía planificada y la apropiación por el estado de la tierra y otros recursos, debe seguir siendo cauteloso. Sin embargo, el país debe dar el paso de la colectivización de la tierra para su privatización.

\section{CONCLUSIÓN}

Ciertamente los DUAT es un derecho real de posesión, que atendiendo a su extensión y contenido, nos hallaremos en algunas de las clases mencionadas anteriormente, usufructo, arrendamiento, enfiteusis, pero no es un derecho de propiedad cuya titularidad pueda adquirir un particular bajo la Constitución de Mozambique en la actualidad, pues la misma solo permite la transmisión del derecho de los DUAT bajo su autoritas, y en consecuencia, bajo el Derecho administrativo, si bien su ejercicio bajo los DUAT se permite sean regulados a través del Derecho privado hasta el limite de su duración y mientras no exista un interés general.

Actualmente, hay un sector doctrinal en Mozambique que quiere avanzar hacia un derecho privado mas amplio para los DUAT. Sin embargo, si bien cabe diferenciar los derechos de uso contenidos en el derecho real de propiedad, la posesión sin ser titular (arrendamiento, usufructuario,..) es un derecho limitado, que si bien permite como derecho real tener acceso al crédito, no es equiparable a la propiedad.

Por otra parte, señalar que las modificaciones pasan por un cambio más profundo y ajustado a la técnica jurídica, y se hace necesario contar con garantías y seguridad en el título del derecho real, porque seria una ficción jurídica conferir a la posesión la categoría de "propiedad del derecho de uso y disfrute (DUAT)". Esto no existe actualmente en Mozambique, donde el Estado cuando recibe ofertas de grandes fondos de inversiones extranjeros, no renuevan los DUAT y conceden el derecho de uso y disfrute a grandes cadenas hoteleras cuando se ubican en la costa, o cuando se descubren recursos mineros, o de gas, y provoca la salida de los agricultores y de la comunidad local, porque se carece de un Registro equivalente a lo que sería nuestro Registro de la Propiedad que da garantías y seguridad jurídica al título de propiedad o de posesión. 


\section{BIBLIOGRAFÍA}

FERNÁNDES, J. P. Dicionário Jurídico da Administração bens do domínio publico. Público, volume IV, Lisboa 1991.

Palma Fernández, J. L. "Hacia un Derecho Administrativo Agrario". Actualidad Administrativa, Sección Doctrina, Ref. XLVIII, pág. 821, tomo 2, Editorial LA LEY, 1999.

Albaladejo García, M. "El usufructo de la nuda propiedad". A.D.C., abril-junio, 1959.

Alonso Pérez, M. "Meditaciones sobre la esencia y funciones de la posesión”. Diario La Ley, tomo 3, Editorial LA LEY, 1986.

Ascensão, J. "Direito Civil - Reais", Coimbra Editora, 1993.

Caetano, M. "Manual de Direito Administrativo", 10ª Edição Reimpressão, Vol. II, Almedina, 1994.

Chiziane, E. "Lei de Terra entre a Lei e as praticas na defesa de direitos sobre a terra" in MANDAMULE, U (Coordenação). "Terra, Poder e Desenvolvimento em Moçambique", Escolar Editora, Maput, 2017.

Cornu, M. "Vocabulario jurídico" Asociación Henri Capitant, cuadriga/PUF, 2001.

Covo Olvera, T. "Esta doctrina forma parte del libro "Régimen jurídico de los bienes de las entidades locales", edición n. ${ }^{\circ} 1$, Editorial LA LEY, Madrid, 2006.

Durang, T. AND TANner, C. "Access to Land and Other Resources for Local Communities in Mozambique: Current Examples from Manica Province", Paper Presented to the Green Agri Net Conference on Land Administration in Practice, Denmark, April 1-2, 2004.

GonZÁLez Martínez, A. "La enfiteusis: aspectos básicos de esta institución”. @ Revista de la Facultad de Ciencias Sociales y Jurídicas de Elche Volúmen I - Número 4 - Enero de 2009.

GunE, B. "Da natureza juridica do direito de uso e aproveitamento da terra em Mozambique", Tesis de maestría, Faculdade de Direito-Universidade Eduardo Mondlane, Maputo, 2006.

Gune, B. "Natureza juridica do direito de uso e aproveitamento da terra em Moçambique" (Dissertação de mestrado), FDUEM- Maputo, 2005.

Gutiérrez Jerez, L. J. "La hipotecabilidad del derecho de usufructo". Actualidad Civil, N. o 20, Quincena del 16 al 30 Nov. tomo 2, LA LEY, 2009.

Leciñena Ibarra, Ascensión. "Concepto legal de usufructo". Esta doctrina forma parte del libro" Tratado de usufructo ", edición n. ${ }^{\circ}$ 1, Editorial LA LEY 2016.

Pereira, C. E. and Baltazar, R. "Reflexões sobre o regime jurídico da terra". Editor Elvetas, 2005.

PInto, R. "Direitos Reais de Moçambique”, ICJ-FDUL, Almedina, Coimbra, 2006.

Quadros, M. C. "Manual de Direito da Terra", CFJJ, Maputo, 2004.

Rodríguez De Santiago, J. M. "Artículo 33 CE: Derecho a la propiedad privada y a la herencia". Diario La Ley, 25 de Mayo de 2018.

Welligton D, Thwala. Experiência sul-africana na reforma agraria, in www.landaction.org/gallery/ South\%20African\%20Land\%20Reform-Portuguese.pdf. 